
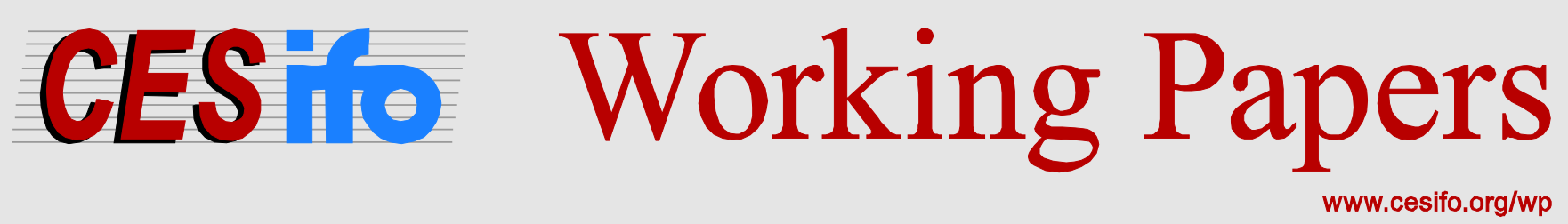

\title{
How Antitrust Enforcement Can Spur Innovation: Bell Labs and the 1956 Consent Decree
}

\author{
Martin Watzinger \\ Thomas A. Fackler \\ Markus Nagler \\ Monika Schnitzer
}

CESIFO WORKING PAPER NO. 6351

CATEGORY 11: INDUSTRIAL ORGANISATION

FEBRUARY 2017

An electronic version of the paper may be downloaded

- from the SSRN website:

- from the RePEc website:

- from the CESifo website:

wWw.SSRN.com

www.RePEc.org

www.CESifo-group.org/wp 


\title{
How Antitrust Enforcement Can Spur Innovation: Bell Labs and the 1956 Consent Decree
}

\begin{abstract}
We study the 1956 consent decree against the Bell System to investigate whether patents held by a dominant firm are harmful for innovation and if so, whether compulsory licensing can provide an effective remedy. The consent decree settled an antitrust lawsuit that charged Bell with having foreclosed the market for telecommunications equipment. The decree forced Bell to license all its existing patents royalty-free. The compulsory licensing increased follow-on innovation building on Bell patents by $17 \%$. This effect is driven mainly by young and small companies. Yet, innovation increased only outside the telecommunications equipment industry, suggesting that compulsory licensing without structural remedies is ineffective in ending market foreclosure.
\end{abstract}

JEL-Codes: O300, O330, O340, K210, L400.

Keywords: innovation, antitrust, intellectual property, compulsory licensing.

\author{
Martin Watzinger \\ Ludwig-Maximilians University \\ Akademiestraße 1 \\ Germany - 80799 Munich \\ martin.watzinger@econ.lmu.de \\ Markus Nagler \\ Ludwig-Maximilians University \\ Akademiestraße 1 \\ Germany - 80799 Munich \\ markus.nagler@econ.Imu.de
}

\author{
Thomas A. Fackler \\ Ludwig-Maximilians University \\ Ludwigstraße 28 \\ Germany - 80539 Munich \\ thomas.fackler@econ.Imu.de \\ Monika Schnitzer* \\ Ludwig-Maximilians University \\ Akademiestraße 1 \\ Germany - 80799 Munich \\ schnitzer@econ.lmu.de
}

\section{*corresponding author}

February 7, 2017

We thank Iain Cockburn, Scott Kominers, John van Reenen, Mark Schankerman, Scott Stern and seminar participants at Boston University, the Frankfurt School of Finance and Management, KU Leuven, and MIT Sloan as well as CEPR Entrepreneurship Stockholm and Applied IO London, Druid Copenhagen, and many other conferences for helpful comments and suggestions. Financial support by Deutsche Forschungsgemeinschaft through CRC TRR 190 is gratefully acknowledged. Fackler and Nagler thank for financial support the Elite Network of Bavaria through Evidence-Based Economics. Nagler gratefully acknowledges a scholarship for doctoral students by the DAAD. Nagler thanks the MIT Department of Economics and Fackler thanks NYU Stern for their hospitality while writing parts of this paper. 


\section{Introduction}

Innovation is a key driver of economic growth. One of the main instruments governments use to foster innovation is the patent system. A patent gives the right to exclude others from using the patented inventions in order to stimulate innovation. However, there is a growing concern that dominant companies might use patents strategically to deny potential entrants, often small technology-oriented start-ups, access to key technologies in an attempt to foreclose the market. ${ }^{1}$ As start-ups are thought to generate more radical innovations than incumbents, market foreclosure may harm technological progress and economic growth (Baker, 2012). ${ }^{2}$ To address this problem many critics call for antitrust policies as a remedy (Wu, 2012; Waller and Sag, 2014). Yet, up to now there are no empirical studies showing that antitrust enforcement can effectively promote innovation.

In this paper we investigate whether patents held by a dominant firm are harmful for follow-on innovation, and if so, whether antitrust enforcement in the form of compulsory licensing of patents provides an effective remedy. We advance on these questions by analyzing the effects of one of the most important antitrust rulings in U.S. history: The 1956 consent decree against the Bell System. This decree settled a seven-year old antitrust lawsuit that sought to break up the Bell System, the dominant provider of telecommunications services in the U.S., because it allegedly monopolized "the manufacture, distribution, and sale of telephones, telephone apparatus and equipment" (Antitrust Subcommittee, 1958, p.1668). Bell was charged with having foreclosed competitors from the market for telecommunications equipment because its operating companies had exclusive supply contracts with its manufacturing subsidiary Western Electric and because it used exclusionary practices such as the refusal to license its patents.

The consent decree contained two main remedies. The Bell System was obligated to license all its patents royalty-free and it was barred from entering any industry other than telecommunications. As a consequence, 7,820 patents or $1.3 \%$ of all unexpired U.S. patents in a wide range of fields became freely available in 1956. Most of these patents covered technologies from the Bell Laboratories (Bell Labs), the research subsidiary of the Bell System, arguably the most innovative industrial laboratory in the world at the time. The Bell Labs produced path-breaking innovations in telecommunications such as the cellular telephone technology or the first transatlantic telephone

\footnotetext{
${ }^{1}$ Derek Thompson, "America's Monopoly Problem", The Atlantic, October 2016; Robert B. Reich, "Big Tech Has Become Way Too Powerful," The New York Times, September 18, 2015, p. SR3; Michael Katz and Carl Shapiro "Breaking up Big Tech Would Harm Consumer," The New York Times, September 28, 2015, p. A24; Thomas Catan "When Patent, Antitrust Worlds Collide," Wall Street Journal, November 14, 2011.

${ }^{2}$ For example, Akcigit and Kerr (2010) show that start-ups do more explorative research and Foster et al. (2006) show that in the retail sector the fast pace of entry and exit is associated with productivity-enhancing creative destruction.
} 
cable. But more than half of its patents were outside the field of telecommunications because of Bell's part in the war effort in World War II and its commitment to basic science. Researchers at Bell Labs are credited for the invention of the transistor, the solar cell, and the laser, among other things.

The Bell case is uniquely suited to investigate the effects of compulsory licensing as an antitrust measure for two reasons: First, it allows to study the effects of compulsory licensing without any confounding changes in the market structure. In compulsory licensing cases, antitrust authorities usually impose structural remedies such as divestitures, which makes it difficult to separate the innovation effects of changes in the market structure from the innovation effects of changes in the licensing regime. Yet, in the case of Bell no structural remedies were imposed, despite the original intent of the Department of Justice. This was due to the intense lobbying of the Department of Defense as Bell was considered vital for national defense purposes.

Second, Bell's broad patent portfolio enables us to measure the effect of compulsory licensing on follow-on innovation in different competitive settings. $42 \%$ of Bell's patents were related to the telecommunications industry. In this industry, Bell was a vertically integrated monopolist who allegedly foreclosed rivals. The remaining $58 \%$ of Bell's patent portfolio had its main application outside of telecommunications. In these industries, Bell was not an active market participant. By looking at the differential effects of compulsory licensing inside and outside of the telecommunications industry we can distinguish the effects of potential foreclosure of patents and of potential bargaining failures that are inherent in the patent system.

Our analysis shows that compulsory licensing increased follow-on innovation that builds on Bell patents. This effect is driven mainly by young and small companies. But the positive effects of compulsory licensing were restricted to industries other than the telecommunications equipment industry. This suggests that Bell continued to foreclose the telecommunications market even after the consent decree took effect. Thus, compulsory licensing without structural remedies appears to be an ineffective remedy for market foreclosure. The increase of follow-on innovation by small and young companies is in line with the hypothesis that patents held by a dominant firm are harmful for innovation because they can act as a barrier to entry for small and young companies who are less able to strike licensing deals than large firms (Lanjouw and Schankerman, 2004; Galasso, 2012). Compulsory licensing removed this barrier in markets outside the telecommunications industry, arguably unintentionally so. This fostered follow-on innovation by young and small companies and contributed to the long run technological progress in the U.S.

Looking at the results in more detail, we first consider the effect of compulsory licensing on innovations that build on Bell patents. We measure follow-on innovation by the number of patent citations Bell Labs patents received from other companies that 
patent in the U.S. We find that in the first five years follow-on innovation increased by $17 \%$ or a total of around 1,000 citations. Back-of-the-envelope calculations suggest that the additional patents other companies filed as a direct result of the consent decree had a value of up to $\$ 5.7$ billion in today's dollars. More than two-thirds of the increase is driven by young and small companies and individual inventors unrelated to Bell. Start-ups and individual inventors increase follow-on innovation by $32 \%$ while for large and old companies the increase is only around 6\%. Robustness checks show that the increase in follow-on innovation is not driven by simultaneous contemporary shocks to technologies in which Bell was active or by citation substitution.

The increase in follow-on innovation by other companies is accompanied by a decrease in follow-on innovation by Bell, but this negative effect is not large enough to dominate the positive effect on patenting by others. The limited negative response by Bell is most likely due to the fact that at the time of the consent decree, Bell was a regulated monopolist subject to rate of return regulation. Yet, the consent decree changed the direction of Bell's research. Bell shifted its research program to focus more on telecommunications research, the only business Bell was allowed to be active in.

In a second step we split the increase in follow-on innovation by industry. We do not find any increase in innovation in the telecommunications industry, the aim of the regulatory intervention. Compulsory licensing fostered innovation only outside of the telecommunications industry. This pattern is consistent with historical records that Bell continued to use exclusionary practices after the consent decree took effect and that these exclusionary practices impeded innovation (Wu, 2012). As no structural remedies were imposed Bell continued to control not only the production of telephone equipment but was - in the form of the Bell operating companies - also its own customer. This made competing with Bell in the telecommunications equipment market unattractive even after compulsory licensing facilitated access to Bell's technology. For example, the Bell operating companies refused to connect any telephone that was not produced by Western Electric, the manufacturing subsidary of the Bell System (Temin and Galambos, 1987, p.222). In other industries, compulsory licensing was effective to foster innovation by young and small companies since Bell as the supplier of technology did not control the product markets through vertical integration or via exclusive contracts.

Although the 1956 consent decree was not effective in ending market foreclosure, it permanently increased the scale of U.S. innovation. In the first five years alone, the number of patents increased by $25 \%$ in fields with compulsorily licensed patents compared to technologically similar fields without; and it continued to increase thereafter. This increase is again driven by small and new companies outside the telecommunications industry. We find only a small increase in patents related to the production of 
telecommunications equipment. This indicates that market foreclosure may slow down technological progress and suggests that antitrust enforcement can have an impact on the long-run rate of technological change. In an in-depth case study we also show that the antitrust lawsuit led to a quicker diffusion of the transistor technology, one of the few general purpose technologies of the post-World War II period.

We contribute to the literature by being the first to empirically investigate the effect of antitrust enforcement on innovation. Our results suggest that foreclosure impedes innovation and that compulsory licensing without structural remedies is not sufficient to overcome foreclosure. Access to technology through compulsory licensing alone does not stimulate market entry and innovation unless there is sufficient access to the product market as well. These insights are relevant not only for antitrust cases about abuse of a dominant market position, such as the Bell case, but also for merger and acquisition cases where compulsory licensing is often used as a remedy when mergers are approved. Our empirical findings support theoretical arguments in the antitrust literature suggesting that to increase innovation, antitrust measures should focus on exclusionary practices and the protection of start-ups (Segal and Whinston, 2007; Baker, 2012; Wu, 2012).

We also contribute to the literature on intellectual property by providing robust causal evidence for the negative effects of patents on follow-on innovation of small and young companies. Our estimate of an increase in follow-on innovation by $17 \%$ is significantly smaller than the increase reported by Galasso and Schankerman (2015b). They study the innovation effect of litigated and invalidated patents and find an increase of $50 \%{ }^{3}$ While our study looks mainly at patents in the electronics and computer industry, Sampat and Williams (2015) consider gene patents and find no effect on follow-on research. The size of our measured effects is consistent with that reported by other studies such as Murray and Stern (2007) and Moser and Voena (2012). They study various measures of follow-on innovation and report an overall impact of a patent removal of about $10-20 \%$ in biotech and chemistry. Our finding of entry of companies as the main mechanism driving the positive innovation effects of compulsory licensing is consistent with Galasso and Schankerman (2015b). They show that the increase in citations can be attributed to small companies citing invalidated patents of large companies.

Finally, this study contributes to our understanding of innovation and growth in the United States in the twentieth century. By providing free state-of-the-art technology to all U.S. companies, compulsory licensing increased U.S. innovation because it opened up new markets for a large number of entrants. This interpretation is consistent with theoretical concepts and historical accounts. Acemoglu and Akcigit (2012) show

\footnotetext{
${ }^{3}$ Litigated patents are selected by importance and by the virtue of having a challenger in court. Thus, the blocking effects of these particular patents might be larger than the average effect for the broad cross-section of patents.
} 
theoretically that compulsory licensing can foster innovation because it enables more companies to compete for becoming the leader in an industry. ${ }^{4}$ In line with this idea, Gordon Moore, the co-founder of Intel, stated that "One of the most important developments for the commercial semiconductor industry (...) was the antitrust suit filed against [the Bell System] in 1949 (...) which allowed the merchant semiconductor industry "to really get started" in the United States (...) [T] here is a direct connection between the liberal licensing policies of Bell Labs and people such as Gordon Teal leaving Bell Labs to start Texas Instruments and William Shockley doing the same thing to start, with the support of Beckman Instruments, Shockley Semiconductor in Palo Alto. This (...) started the growth of Silicon Valley" (Wessner et al., 2001, p. 86) Similarly, Peter Grindley and David Teece opined that "[AT\&T's licensing policy shaped by antitrust policy] remains one of the most unheralded contributions to economic development - possibly far exceeding the Marshall plan in terms of wealth generation it established abroad and in the United States" (Grindley and Teece, 1997).

The remainder of this paper is organized as follows. Section 2 describes the antitrust lawsuit against Bell and the consent decree. In Section 3 we describe the data and the empirical strategy. In Section 4 we show that compulsory licensing increased follow-on innovation and conduct robustness checks. In Section 5 we examine the effectiveness of compulsory licensing as an antitrust measure against foreclosure in the market for telecommunications equipment. In section 6 , we present the long run effects of the consent decree on U.S. patenting. Section 7 presents a case study of the licensing of Bell's transistor technology, the defining general purpose technology of the 20th century. Section 8 concludes.

\section{The Bell System and the Antitrust Lawsuit}

In this section we describe the Bell System and the antitrust lawsuit against Bell. We then discuss the unique features of the case that make it ideally suited for our empirical analysis.

\subsection{The Bell System was a Vertically Integrated Monopolist}

In 1956, American Telephone \& Telegraph (AT\&T) was the dominant provider of telecommunications services in the U.S. Through its operating companies, it owned or controlled $98 \%$ of all the facilities providing long distance telephone services and $85 \%$

\footnotetext{
${ }^{4}$ In the model of Acemoglu and Akcigit (2012), compulsory licensing also makes innovation less profitable because leaders are replaced more quickly. In the case of Bell, compulsory licensing was selectively applied to only one company which was not active in the newly created industries. This suggests that there was no disincentive effect and that our empirical set-up cleanly measures the effects of an increase in competition on innovation.
} 
Figure 1: The structure of the Bell system
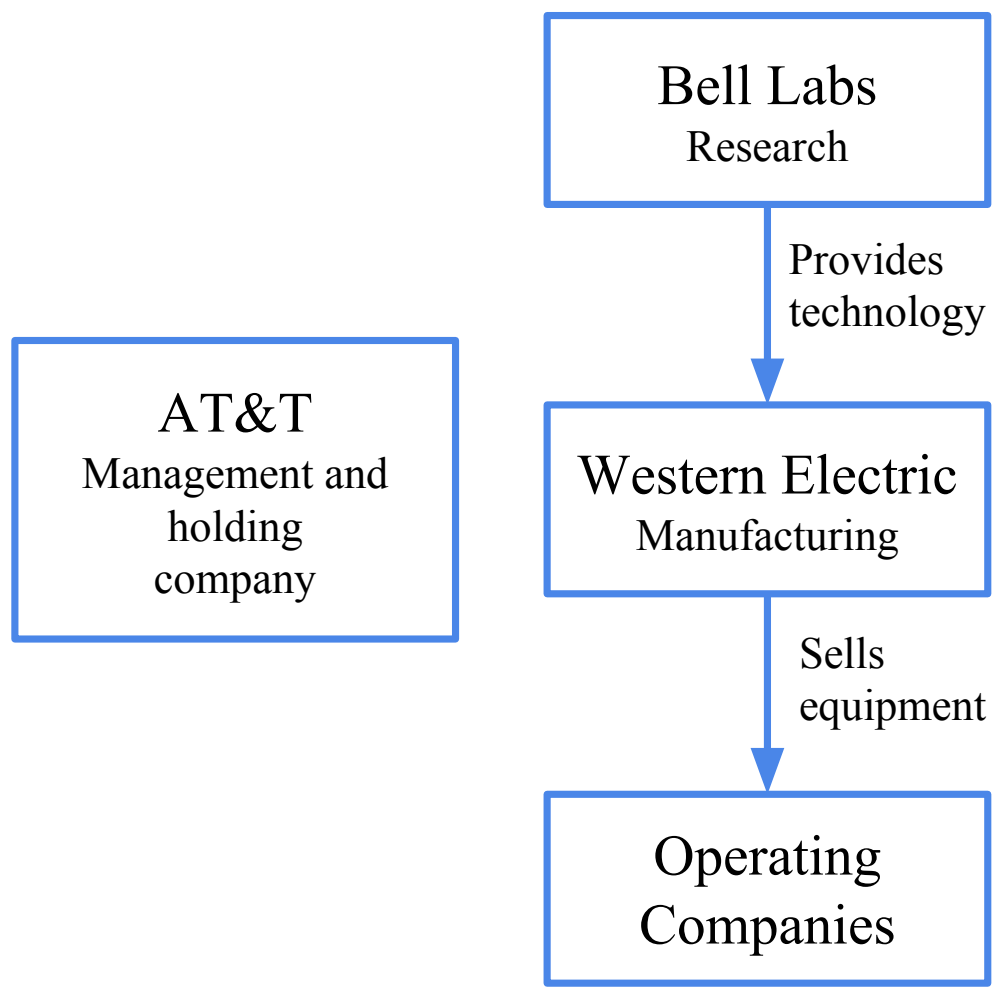

of all facilities providing short distance telephone services. These operating companies bought all of their equipment from Western Electric, the manufacturing subsidiary of AT\&T. As a consequence, Western Electric had a market share in excess of $90 \%$ in the production of telecommunications equipment. Western Electric produced telecommunications equipment based on the research done by the Bell Laboratories, the research subsidiary of AT\&T and Western Electric. All these companies together were known as the Bell System, stressing its complete vertical integration (Figure 1). In terms of assets, AT\&T was by far the largest private corporation in the world in 1956, employing 598,000 people with an operating revenue of $\$ 2.9$ billion or $1 \%$ of the U.S. GDP at the time (Antitrust Subcommittee, 1959, p.31).

The Bell System held patents on many key technologies in telecommunications, as well as a large number of patents in many other fields. Between 1940 and 1970, Bell filed on average $\sim 543$ patents or $1 \%$ of all U.S. patents each year (see Figure 2). More than $70 \%$ of the patents protected inventions of the Bell Laboratories (Bell Labs), arguably the most innovative industrial laboratories in the world at the time.

The Bell Labs were unique in their commitment to basic research. When the Bell Labs were founded in 1925, no one knew which part of science might yield insights for the problems of electric communication (Rosenberg, 1990; Nelson, 1962, p.31). As a result, the Bell System decided that - besides supporting the day-to-day need of the System - the Bell Labs would engage in basic science, assuming it would eventually 
yield products for some part of the large Bell System (Gertner, 2012; Nelson, 1959; Arora et al., 2015, p. 31). ${ }^{5}$

The Bell Labs produced path-breaking basic and applied research. Scientists at Bell are credited for the development of radio astronomy (1932), the transistor (1947), cellular telephone technology (1947), information theory (1948), solar cells (1954), the laser (1957), and the Unix operating system (1969). The 1950 staff of Bell Labs alone consisted of four future Nobel Laureates in physics, one Turing Award winner, five future U.S. National Medals of Science recipients and 10 future IEEE Medals of Honor recipients. In 1950, Bell Labs employed 6,000 people, one third of whom were professional scientists and engineers (Nelson, 1962; Temin and Galambos, 1987). This was $1 \%$ of the entire science and engineering workforce in the U.S. at the time. ${ }^{6}$

\subsection{The Antitrust Lawsuit}

On January 14, 1949 the United States Government filed an antitrust lawsuit with the aim to split AT\&T from Western Electric. ${ }^{7}$ The complaint charged that Western Electric and AT\&T had been engaged in the monopolization of the manufacture, distribution and sale of telecommunications equipment in violation of the Sherman Antitrust Act of 1890 (Antitrust Subcommittee, 1959, p.46). According to the complaint, Bell was closing the market to all other buyers and sellers of telecommunications equipment by exclusionary practices including exclusive contracts and the refusal to license patents. ${ }^{8}$

To correct this, the government sought three main remedies. First, Western Electric was to be separated from AT\&T, split into three competing companies, and to transfer all of its shares of the research subsidiary Bell Laboratories to AT\&T. Second, AT\&T was to buy telephone equipment only under competitive bidding and all ex-

\footnotetext{
${ }^{5}$ According to the first head of basic and applied research at Bell Labs, Harold Arnold, his department would include "the field of physical and organical chemistry, of metallurgy, of magnetism, of electrical conduction, of radiation, of electronics, of acoustics, of phonetics, of optics, of mathematics, of mechanics, and even of physiology, of psychology and meteorology". This broad focus led to major advances in basic science, but also to a large number of unused patents. For example, an investigation of the FCC in 1934 reported that Bell owned or controlled 9,255 patents but actively used only 4,225 covered inventions (Antitrust Subcommittee, 1958, p.3842).

${ }^{6}$ According to the National Science Foundation, the number of workers in S\&E occupations was 182,000 in the U.S. in 1950. Source: https://www.nsf.gov/statistics/seind12/c3/c3h.htm - last accessed August 30, 2016.

${ }^{7}$ This account of facts follows largely the final report to the Antitrust Subcommittee of the House on the Bell Consent Decree Program (Antitrust Subcommittee, 1959).

${ }^{8}$ For example, Bell allegedly forced competitors "engaged in the rendition of telephone service to acquire AT\&T patent license under threat of (...) patent infringement suits," or refused "to issue patent licenses except on condition" to be able to control the telephone manufacturer or by "refusing to authorize the manufacture (...) of telephones (...) under patents controlled by (...) the Bell System" or by "refusing to make available to the telegraphy industry the basic patents on the vacuum tube" that are essential for telegraphy to compete with telephone or by refusing to purchase equipment "under patents which are not controlled by Western or AT\&T, which are known to be superior" (Antitrust Subcommittee, 1958, p.3838).
} 
Figure 2: Size and diversity of Bell's patent portfolio

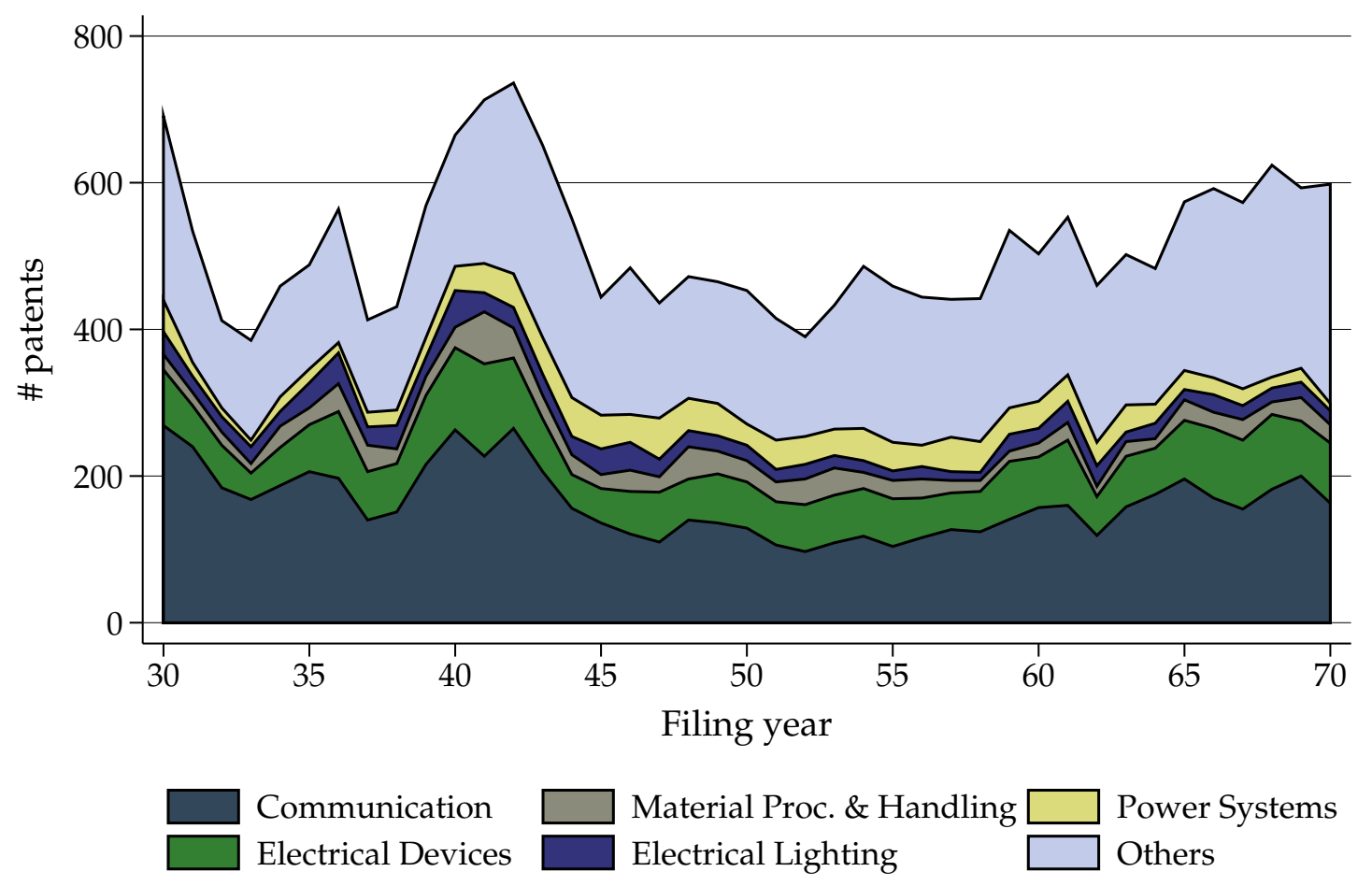

Notes: This figure shows the number of Bell patents in different technology subcategories over time. The subcategories aggregate the U.S. Patent Classification (USPC) following the scheme of Hall et al. (2001). We re-assign patents in the field of Optics to the Communication patents, as optics in the form of optical fiber played a large role in the development of communication technology starting in the 1960s. Of the compulsorily licensed patents published before January 1956 only 29 were in the field of Optics. The data are from the Worldwide Patent Statistical Database (PATSTAT) of the European Patent Office. 
clusive contracts between AT\&T and Western were to be prohibited. Third, the Bell System was to be forced to license all its patents for reasonable and non-discriminatory royalties (Antitrust Subcommittee, 1959, p.33). ${ }^{9}$ Yet, none of this would happen.

The case ended with a consent decree on January 24, 1956, containing two remedies: First, the Bell System had to license all its patents issued prior to the decree royalty free to any applicant, with the exception of RCA, General Electric and Westinghouse who already had cross licensing agreements with Bell (the so called B-2 agreements). All subsequently published patents had to be licensed for reasonable royalties. As a consequence of the consent decree, 7,820 patents in 266 USPC technology classes and 35 technology subcategories (Figure 13 in Appendix A) or 1.3\% of all unexpired U.S. patents became freely available. Second, the Bell System was barred from engaging in any business other than telecommunications.

The decree was hailed by antitrust officials as a "major victory", but already in 1957 the Antitrust Subcommittee of the Committee on the Judiciary House of Representatives started to investigate whether the decree of AT\&T was in the public interest. The final report issued in 1959 pulled the decree to pieces: "the consent decree entered in the A.T. \& T. case stands revealed as devoid of merit and ineffective as an instrument to accomplish the purposes of the antitrust laws. The decree not only permits continued control by A.T. \& T. of Western, it fails to limit Western's role as the exclusive supplier of equipment to the Bell System, thereby continuing monopoly in the telephone equipment manufacturing industry."

The hearings of the Senate subcommittee uncovered a timeline of cozy back and forth negotiations and intense lobbying by the Department of Defense (DoD). The DoD intervened on behalf of Bell because it relied on the research of the Bell Labs. In World War II, the Bell Labs had been instrumental in inventing the superior radar systems of the Allies. They also engaged in around a thousand different projects, from tank radio communications to enciphering machines for scrambling secret messages (Gertner, 2012, p.59 ff.). ${ }^{10}$ In the following years, Bell Labs continued to work for the DoD, for example by operating the Sandia National Laboratories, one of the main development facilities for nuclear weapons.

After the complaint was filed in January 1949, Bell sought and obtained a freeze of the antitrust lawsuit in early 1952 with support of the the DoD, on the grounds that Bell was necessary for the war effort in Korea. In January 1953, after Dwight D. Eisenhower took office, Bell began to lobby for the final dismissal of the case. The argument was that the Bell System was too important for national defense and

\footnotetext{
${ }^{9}$ There were two minor remedies: First, AT\&T was not to be allowed to direct the Bell operating companies which equipment to purchase and second, all contracts that eliminated or restrained competition were to be ceased.

${ }^{10}$ To highlight the engagement of Bell, we show in Figure 14 in Appendix A.2 the patenting activity of Bell in radar and cryptography during World War II.
} 
thus should be kept intact. The government followed this argument and the Attorney General Herbert Brownell Jr. asked Bell to submit concessions "with no real injury" that would be acceptable in order to settle (Antitrust Subcommittee, 1959, p.55)

In May 1954, AT\&T presented and in June 1954 submitted to the Department of Justice a checklist of concessions that would be an acceptable basis for a consent decree. The only suggested major remedy was the compulsory licensing of all Bell patents for reasonable royalties. To support its position, Charles Erwin Wilson, the Secretary of Defense, wrote Herbert Brownell Jr., the Attorney General, a memorandum to the effect that the severance of Western Electric from Bell would be "contrary to the vital interests of our nation" (Antitrust Subcommittee, 1959, p. 56). In December 1955, the Department of Justice communicated with AT\&T that it was ready to consider a decree of the "general character suggested [by A. T. \& T.] in its memorandum (...) dated June 4, 1954" (Antitrust Subcommittee, 1959, p.92). Bell agreed.

\subsection{Advantages of the Bell Case for the Empirical Set-Up}

The Bell case has two characteristics that make it ideally suited to measure the innovation effects of compulsory licensing as an antitrust remedy.

First, the consent decree did not impose any structural remedies for the telecommunications market. This allows us to isolate the innovation effect of compulsory licensing without any confounding changes in market structure. The reason why the Department of Justice did not impose any structural remedies is unclear. The final conclusion of the Antitrust Subcommittee blamed the lack of intent of the Attorney General to pursue Bell and the intense lobbying of the Department of Defense for the fact that no structural remedies were imposed (Antitrust Subcommittee, 1959, p.292). In contrast, the presiding judge Stanley N. Barnes stated that in his opinion it was enough to confine Bell to the regulated telecommunications market in order to prevent excessive prices and to end the exclusion of other suppliers (Antitrust Subcommittee, 1959, p.317).

Second, due to Bell Labs' commitment to basic science and its role in the war effort, Bell held a large number of patents unrelated to telecommunications, in industries in which it was not an active market participant. This gives us the opportunity to measure how the innovation effect of compulsory licensing depends on the market structure. In the telecommunications industry, Bell was vertically integrated. Hence Bell was not only a dominant player in the production of the technology used for telephone equipment, but it also controlled the production of telephone equipment (Western Electric), as well as the product market for telephone equipment through its operating companies. In all other industries, Bell was a supplier of technology, but was not active in production. Even more, the consent decree explicitly banned Bell from ever entering into these businesses which meant that it effectively preserved the 
Figure 3: Compulsorily Licensed Patents by Industry
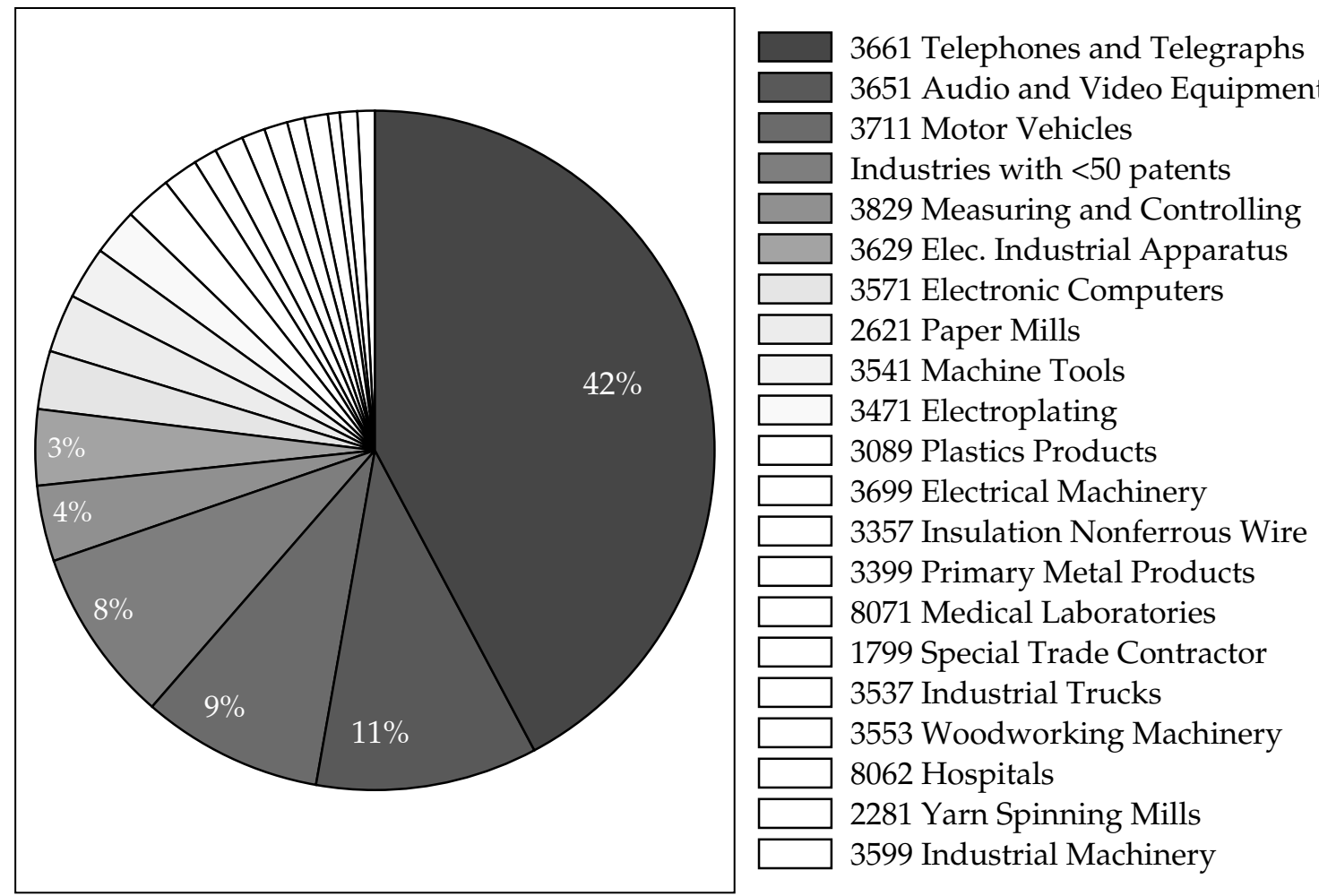

Notes: The pie chart shows the distribution of compulsorily licensed patents by most likely industry. We assign patents to the most likely 4-digit SIC industry using the data of Kerr (2008). The data are from the Worldwide Patent Statistical Database (PATSTAT) of the European Patent Office.

market structure inside and outside of the telecommunications industry.

To visualize the broad patent portfolio of Bell we use the data of Kerr (2008) to assign the most likely 4-digit SIC industry group to each USPC class (Figure 3). ${ }^{11}$ Around $42 \%$ of all Bell's patents have their most likely application in Bell's core business of producing telephones and telegraphs (SIC 3661). The remainder is spread across a large number of fields with an emphasis on electronics and industrial commercial machinery and computer equipment. ${ }^{12}$

\section{Data and Empirical Strategy}

For our estimation, we use comprehensive patent data for the U.S. from the Worldwide Patent Statistical Database (PATSTAT) of the European Patent Office. In this data, we identify all compulsorily licensed patents of the Bell System with a list of patent numbers published in the "Hearings before the Antitrust Subcommittee" of the U.S.

\footnotetext{
${ }^{11}$ We thank Bill Kerr for sharing his data.

${ }^{12}$ In Figure 13 in Appendix A.1 we show the compulsorily licensed patents split by technology subcategories following Hall et al. (2001). Only 31\% of all Bell patents are in the field of telecommunications and the remaining patents are spread over 34 other subcategories.
} 
Congress on the consent decree of Bell in May 1958 (Antitrust Subcommittee, 1958). ${ }^{13}$

In an ideal world, we would compare the number of realized follow-on innovations building on Bell patents with and without the consent decree. The problem is, however, that this is not possible: First, a census of follow-on innovations does not exist and second, we can observe only the state of the world in which the compulsory licensing of Bell patents happened but not the counterfactual situation without the consent decree.

To measure follow-on innovations we use patent citations. Bell patents could be freely licensed after the consent decree, but patents that built on licensed Bell patents still had to cite them. Thus, we can use patent citations as a measure for follow-on innovations even though patents had lost their power to exclude competitors (Williams, 2015). The advantage of this measure is that, in contrast to most alternative measures such as new products or R\&D spending, citations are consistently available from 1947 onward. ${ }^{14}$ Citations have the additional advantage that they have a high frequency which allows a precise measurement of effects. The caveat is that some citations might have been added by the patent examiner, which adds noise to the measure (Alcacer and Gittelman, 2006; Alcacer et al., 2009).

To construct a counterfactual for the compulsorily licensed Bell patents we use as control group all other patents that are published in the same year, that have the same total number of citations as the Bell patents in the five years prior to 1949, and that are in the same USPC technology class. By conditioning on the publication year and prior citations we control for the fact that, on average, young and high quality patents are cited more often. By conditioning on the same technology class we control for the number of companies that are active in the same field (i.e., for the number of potential follow-on inventors) and for technology-specific citation trends.

We can interpret our results causally under the assumption that in the absence of the consent decree the Bell patents would have received the same number of citations as the control patents did (parallel trend assumption). More specifically, the identifying assumption is that conditioning on the control variables removes any systematic difference in follow-on citations between Bell and the control patents that is not due to compulsory licensing.

One potential concern about this identification strategy might be that the antitrust authorities chose to compulsorily license Bell patents for a reason related to the poten-

\footnotetext{
${ }^{13}$ The list is the complete list of all patents owned by the Bell System in January 1956. It also includes patents of Typesetter Corp. which were explicitly excluded from compulsory licensing in Section X of the consent decree. We assume that these patents are unaffected.

${ }^{14}$ In 1947 the USPTO started to publish citations of prior art on the front page of the patent (Alcacer et al., 2009).The first patent to include prior art was issued on February 4, 1947. Yet, inventions were evaluated against the prior art already since the passage of the Patent Act of 1836. Prior to 1947, however, the prior art was available only from the "file history" of the issued patent, which is not contained in Patstat.
} 
tial of follow-on research of these patents. According to the complaint and historical records, compulsory licensing was imposed because Bell used patents to block competitors in the field of telecommunications equipment. So if blocking patents are also patents that in the absence of compulsory licensing would have experienced particularly strong follow-on innovation then we might overestimate the effect of the consent decree.

Yet, this does not appear to be likely. In the absence of compulsory licensing, Bell's telecommunication patents would have continued to block competitors because the consent decree did not contain any other remedies aimed at restoring competition. Consequently, it seems fair to assume that blocking patents would have continued to receive the same number of citations as the control patents that have the same number of citations in the five years prior to 1949.

Furthermore, this concern obviously does not apply to the $58 \%$ of patents Bell held outside the field of telecommunications. These patents were included in the compulsory licensing regime of the consent decree not because they were blocking, but purely due to their association with the Bell System. Hence, there is no reason to expect any confounding effects.

To strengthen the point that the parallel trend assumption is plausible, we show in Section 4.1 that the number of citations of Bell and control patents was the same before the terms of the consent decree became known. In Section 4.3 we also show that companies that did not benefit from compulsory licensing did not start to cite Bell patents more after the consent decree. Thus, the control patents are a plausible counterfactual for patents both inside and outside of telecommunications.

Another concern might be that Bell's patenting strategy may have changed after the complaint became known. This is why we focus on patents published by 1949 , the year the lawsuit against Bell started. The consent decree stated that only patents published before 1956 were to be compulsorily licensed. As a consequence of this cutoff date, more than $98 \%$ of the patents affected by the consent decree were filed before 1953, and more than $82 \%$ earlier than 1949. This implies that the characteristics of the majority of the affected patents were fixed before the Department of Justice filed its initial complaint. To be on the safe side, we use only patents granted before 1949, but the results do not change when we use all patents affected by the consent decree.

Out of the 7820 Bell patents affected by the Consent decree, 4,731 patents were published before 1949. For 4,533 of these patents (i.e., for 95.8\%) we find in total 70,180 control patents that fulfill the criteria specified above. In our empirical analysis, we use the weights of Iacus et al. (2009) to account for the potentially different number of control patents per Bell patent. ${ }^{15}$

\footnotetext{
${ }^{15}$ Iacus et al. (2009) proposes to use a weight of 1 for the treatment variable and a weight of $N_{\text {Treatment,Strata }} / N_{\text {Control,Strata }} \cdot N_{\text {Control }} / N_{\text {Treatment }}$ where $N_{\text {Control }}$ is the number of control patents in the sample, $N_{\text {Control,Strata }}$ is the number of control patents in a strata defined by the
} 
Table 1 shows summary statistics. In column (1) we report the summary statistics for all patents published between 1939 to 1956. In column (2) we report the summary statistics of all Bell patents that were published between 1939 and 1956 and hence affected by the compulsory licensing rule. Patents published before 1939 had lost their patent protection by 1956 and were therefore not affected by the consent decree. In column (3) we report the summary statistics of the Bell patents published between 1939 and 1948. These are the patents that we use in our baseline regression. ${ }^{16}$ They are affected by the consent decree but published before the lawsuit started and hence unaffected by a potential patenting policy change the lawsuit may have triggered.

The summary statistics of Bell patents differ from those of non-Bell patents. The average non-Bell patent in our data set receives 3.3 citations per patent and $6.1 \%$ of these citations are self-citations. ${ }^{17}$ Bell System patents published in the same time period on average receive 5.2 citations and $13.4 \%$ of these citations are self-citations. ${ }^{18}$ The numbers for the subsample of Bell patents published until 1949 are very similar. They receive on average 4.9 citations of which around $14.2 \%$ are self-citations.

\section{Results: Compulsory Licensing Increased Follow- on Innovation}

Prior to the consent decree, Bell licensed its patents to other companies at royalty rates of $1 \%-6 \%$ of the net sales price. Lower rates applied if a cross-license was agreed upon (Antitrust Subcommittee, 1958, p. 2685). The consent decree lowered these rates to zero and made licensing available without having to enter into a bargaining process with Bell. In this section we estimate whether and if so by how much this compulsory licensing increased follow-on innovations.

\subsection{Timing: The Consent Decree Increased Citations of Other Companies Starting in 1955}

In this section, we estimate the impact of the compulsory licensing on citations looking at the time period 1949-1970. We employ the following difference-in-differences specification:

publication year, the USPC primary class and the number of citations up to 1949. $N_{\text {Treatment }}$ and $N_{\text {Treatment,Strata }}$ are defined analogously. Using these weights we arrive at an estimate for the average treatment effect on the treated.

${ }^{16}$ To make the statistics comparable for affected and not affected patents, we only consider technology classes in which Bell is active.

${ }^{17}$ In the main part of our paper we only use citations by U.S. patents. In the Appendix we run one regression with citations of patents filed in foreign jurisdictions.

${ }^{18}$ Except when explicitly mentioned in the text we correct for self-citations in all our regressions because we are mainly interested to which extent other companies built on Bell Labs patents. 
Table 1: Summary Statistics

\begin{tabular}{|c|c|c|c|}
\hline & $\begin{array}{c}(1) \\
\text { None-Bell } \\
\text { System }\end{array}$ & $\begin{array}{c}(2) \\
\text { Bell } \\
\text { System } \\
\text { Affected }\end{array}$ & $\begin{array}{c}(3) \\
\text { Bell System } \\
\text { Baseline } \\
\text { Sample }\end{array}$ \\
\hline & mean & mean & mean \\
\hline Filing Year & 1944.5 & 1943.6 & 1940.6 \\
\hline Publication Year & 1947.6 & 1946.5 & 1943.1 \\
\hline $\begin{array}{l}\text { \# Years in patent protection after } \\
1956\end{array}$ & 8.6 & 7.5 & 4.1 \\
\hline Total cites & 3.3 & 5.2 & 4.9 \\
\hline Citations by other companies & 3.1 & 4.5 & 4.3 \\
\hline Self Citations & 0.2 & 0.7 & 0.7 \\
\hline $\begin{array}{l}\text { Citations by other companies prior } \\
\text { to } 1949\end{array}$ & 0.3 & 0.9 & 1.4 \\
\hline Observations & 293578 & 7820 & 4731 \\
\hline
\end{tabular}

Notes: The table reports the average filing and publication year, the average number of years until patent expiration and citation statistics for patents published between 1939 and 1956. Column (1) includes all patents of non-Bell System companies in technologies where a Bell System company published at least one patent. Column (2) includes all Bell patents published between 1939 and 1956. Column (3) includes all Bell patents published between 1939 and 1949, the baseline sample of most of our regressions. A citation is identified as a self-cite if the applicant of the cited and citing patent is the same or if both patents belong to the Bell System. The data are from the Worldwide Patent Statistical Database (PATSTAT) of the European Patent Office. 
Figure 4: Effect of Compulsory Licensing on Subsequent Citations

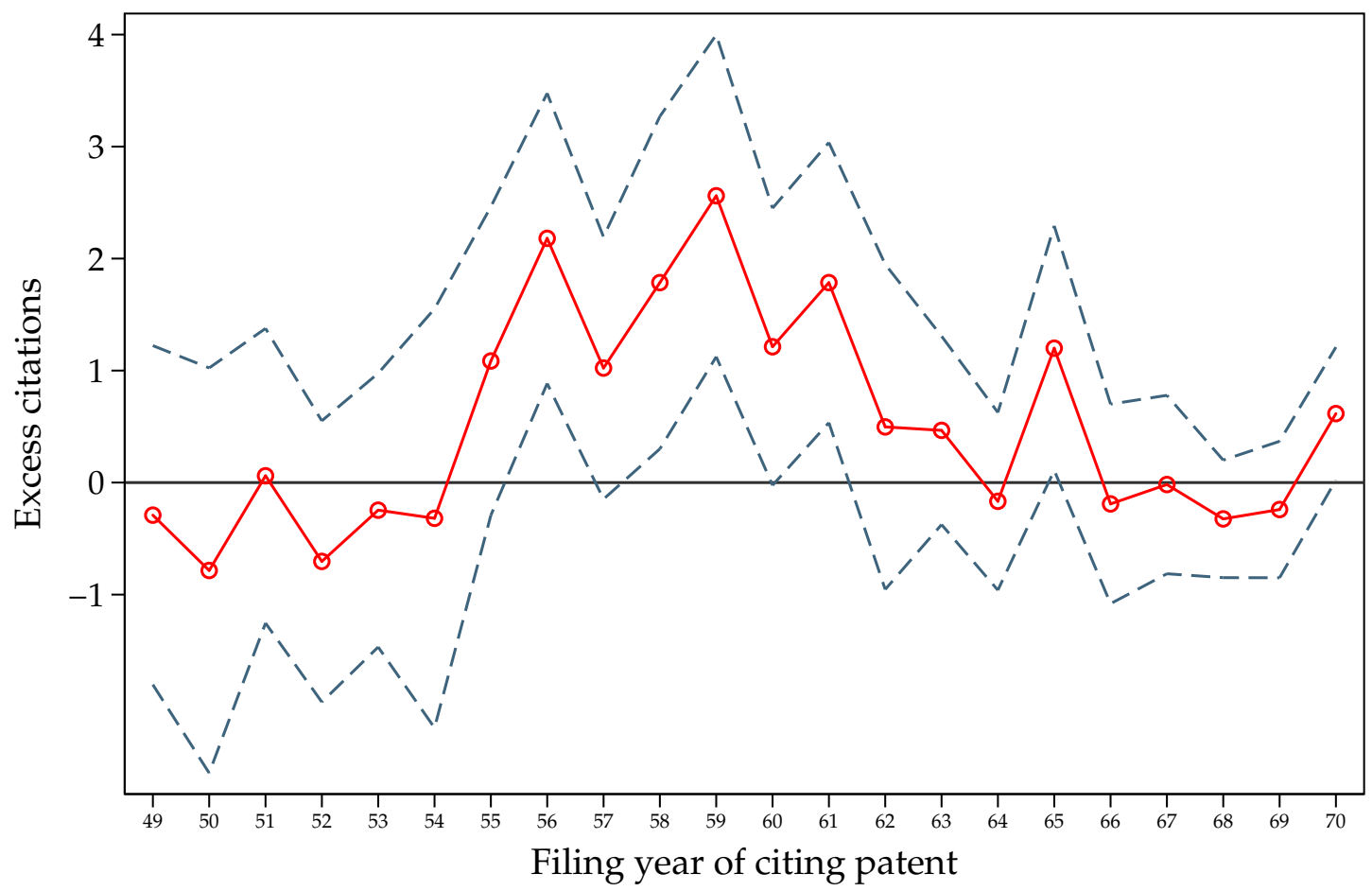

Notes: This graph shows the estimated number of yearly excess citations of patents affected by the consent decree ("Bell patents") relative to patents with the same publication year, in the same threedigit U. S. Patent Classification (USPC) primary class and with the same number of citations up to 1949. To arrive at these estimates we regress the number of citations in each year on an indicator variable that is equal to one if the patent under consideration is affected by the consent decree, and year fixed effects (Equation 1). We correct for self-citations. The dashed line represents the $90 \%$ confidence bands for the estimated coefficient. The sample under consideration contains 4,533 Bell patents and 70,180 control patents. We cannot match 198 Bell patents to control patents. To adjust for the different number of control patents per treatment patent in each stratum, we use the weights suggested by Iacus et al. (2009). The data are from the Worldwide Patent Statistical Database (PATSTAT) of the European Patent Office. 


$$
\# \text { Citations }_{i, t}=\alpha+\beta_{t} \cdot \text { Bell }_{i}+\text { YearF } E_{t}+\varepsilon_{i, t}
$$

where \# Citations $_{i, t}$ is the number of follow-on citations of other companies to patent $i$ in year $t$. Bell $i$ indicates whether the patent $\mathrm{i}$ is owned by the Bell System and is therefore treated. We also include fixed effects for each year $\left(Y e a r F E_{t}\right)$.

Figure 4 shows per year the estimated number of excess citations of Bell patents that were granted before 1949 relative to control patents, $\beta_{t}$ in equation 1. From 1949 to 1954 , the average number of citations of treatment and control patents tracks each other very closely, speaking in favor of parallel trends in citations to Bell patents and to the control patents. In 1955, the average number of citations of other companies to Bell patents starts to increase and it converges again in 1960; 1960 is the average expiration date of the Bell patents in our sample (Table 1). ${ }^{19}$ The yearly coefficients from 1955 to 1960 are mostly significantly different from zero at the $10 \%$ level. ${ }^{20}$

The increase in citations depicted in Figure 4 does not start in 1956, the year of the consent decree, but in 1955. This is plausible because on May 28, 1954, Bell already suggested a consent decree including the compulsory licensing of Bell System patents as described in Section 2. Thus, both the Bell Laboratories and companies building on Bell's patents could have known that compulsory licensing was pending as early as May 1954 (Antitrust Subcommittee, 1959). ${ }^{21}$

This timeline is supported by the cumulative abnormal stock returns for AT\&T stocks shown in Figure 5. ${ }^{22}$ Up to the election of Dwight Eisenhower, cumulative abnormal returns were centered around zero. At the beginning of 1954, cumulative abnormal returns strongly increased to around 11\%. The large uptick in March 1954 is exactly synchronized with the date of a memorandum summarizing a meeting of the Attorney General and Bell management about how to resolve the Bell case (Antitrust Subcommittee, 1958, p. 1956). Shortly thereafter, in May 1954, Bell proposed compulsory licensing as an acceptable remedy to settle the lawsuit. There is no more persistent positive or negative change in the cumulative abnormal return until 1959. In particular, the consent decree itself in 1956 did not seem to have had any more informational value.

We can also infer from Bell's behavior that as early as the first half of 1955, compulsory licensing was expected. According to the consent decree, all patents had to be licensed for free if they were published before January 24, 1956. If they were published

\footnotetext{
${ }^{19}$ From 1861 to 1994 , the term of the patent was 17 years from issuance.

${ }^{20}$ In Appendix B.1 we graphically compare the average yearly number of citations to Bell and to control patents and find the same results.

${ }^{21}$ The first media mentioning of the consent decree against Bell was on May 13, 1955 in the New York Times. Public officials confirmed that top level negotiations are ongoing "looking towards a settlement of the AT\&T case".

${ }^{22}$ The historical stock market data is from CRSP.
} 
Figure 5: Cumulative Abnormal Stock Returns of AT\&T

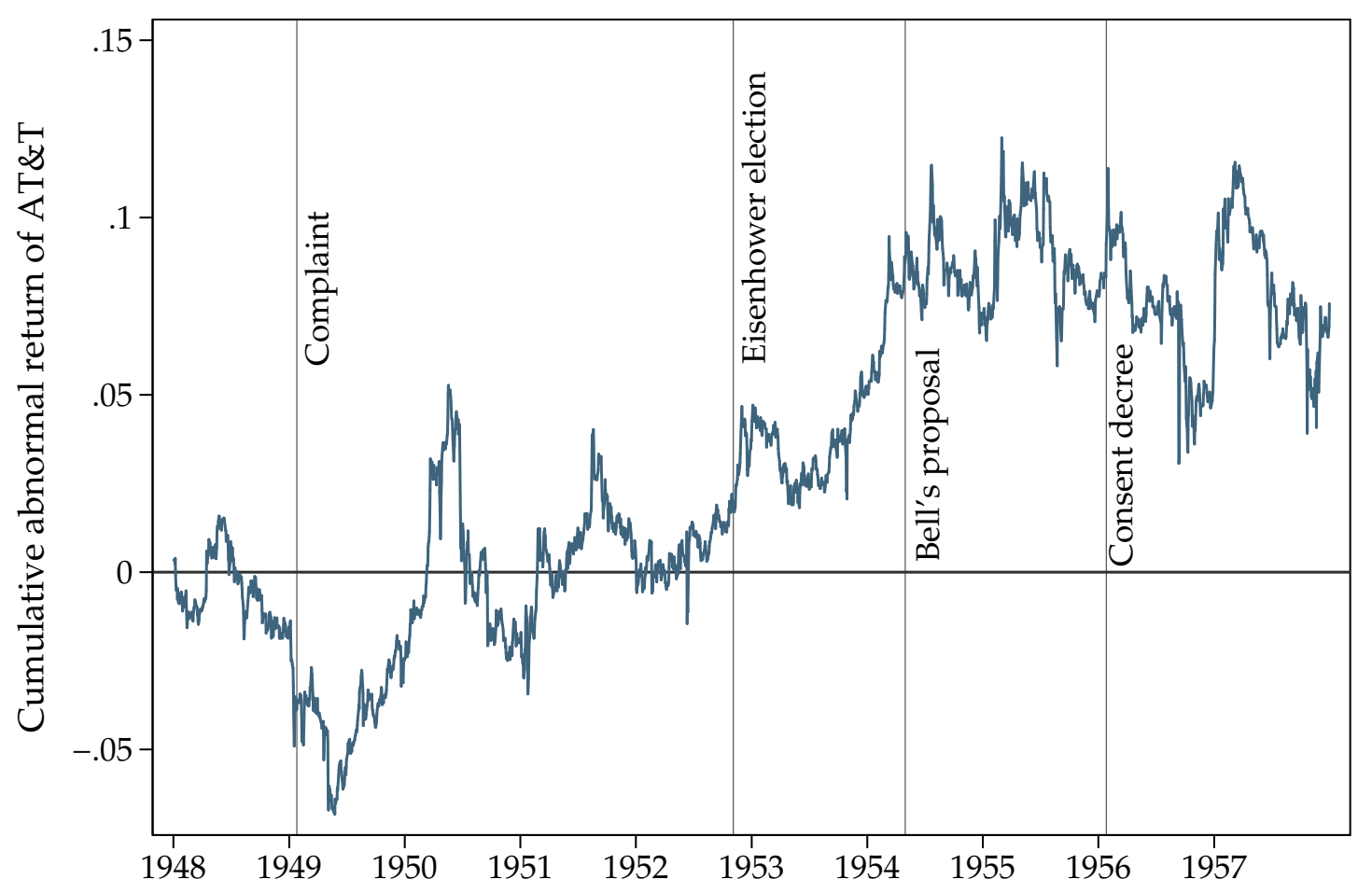

Notes: This figure shows the cumulative abnormal stock return of AT\&T compared to other companies in the Dow Jones index, beginning in January 1948. The events marked in the graph are the beginning of the antitrust lawsuit on January 14, 1949, the presidential election on November 4, 1952, Bell's proposal of compulsory licensing on June 4, 1954, and the consent decree on January 25, 1956. The data are from the Center for Research in Security Prices (CRSP). 
after this cut-off date, they were licensed on a reasonable and non-discriminatory basis. So starting from the date when Bell became aware of the clause it had an incentive to delay the publication of its patents beyond the cut-off date.

According to the data, Bell indeed started to delay its patents at the patent office beginning in the first half of 1955 . To pin down the date, we compare the propensity of a Bell patent to be published with the propensity that control patents are published for a given filing year. In Figure 6, we show these hazard rates of publishing in a particular year for the filing years 1949 and $1953 .^{23}$ For the filing year 1949, the publishing rates per year are very similar for Bell patents and patents from other companies. If at all, Bell patents were published a bit earlier. For the filing year 1953, this picture is reversed: Starting in the first half of 1955, Bell patents had a significantly lower probability of being published. This is consistent with Bell trying to delay the publications of its patents and having credible information about the general outline of the consent decree in the first half of 1955 at the latest.

\subsection{Magnitude: The Consent Decree Increased Citations to Bell Patents by $17 \%$}

We next present our baseline regression. To quantify the size of the effects of the consent decree, we estimate the average yearly effect of the consent decree on citations of other companies for the time period 1949-1960. We employ the following differencein-differences model:

$$
\text { \#Citations }_{i, t}=\beta_{1} \cdot \text { Bell }_{i}+\beta_{2} \cdot I[1955-1960]+\beta_{3} \cdot \text { Bell }_{i} \cdot I[1955-1960]+\varepsilon_{i, t}
$$

where $I[1955-1960]$ is an indicator variable for the treatment period. We define the treatment period as from 1955 to 1960 based on the yearly coefficients in Figure 4.

The results are reported in Table 2 column (1). ${ }^{24}$ In the treatment period, the consent decree resulted in 0.020 additional citations. This implies that, on average, the consent decree increased citations to Bell patents by other companies by $17 \%$ from 1955 to $1960 .{ }^{25}$ Considering only the 4,731 patents published before 1949 , this implies a total increase of 568 citations. If we assume homogeneous effects for all 7,820 patents published up to 1956, the total number of excess citations is 938 . The effect is also positive and statistically significant if we include all patents up to 1956, the year of

\footnotetext{
${ }^{23}$ Hazard rates for all other years are available from the authors upon request.

${ }^{24}$ Note that patents receive fewer citations post treatment because older patents in general receive fewer citations than younger patents. See Figure 15 in Appendix B.1

${ }^{25}$ To determine the percentage increase, we first calculate the number of citations Bell patents would have received in the absence of the treatment (counterfactual), using the coefficients in Table 2 column (1). The counterfactual is $0.115(=0.183-0.004-0.064)$. We then divide the treatment effect, 0.02 , by the counterfactual $(0.02 / 0.115=0.174)$.
} 
Figure 6: Hazard Rates for Publication of Patents by Filing Year

(a) Filing year 1949

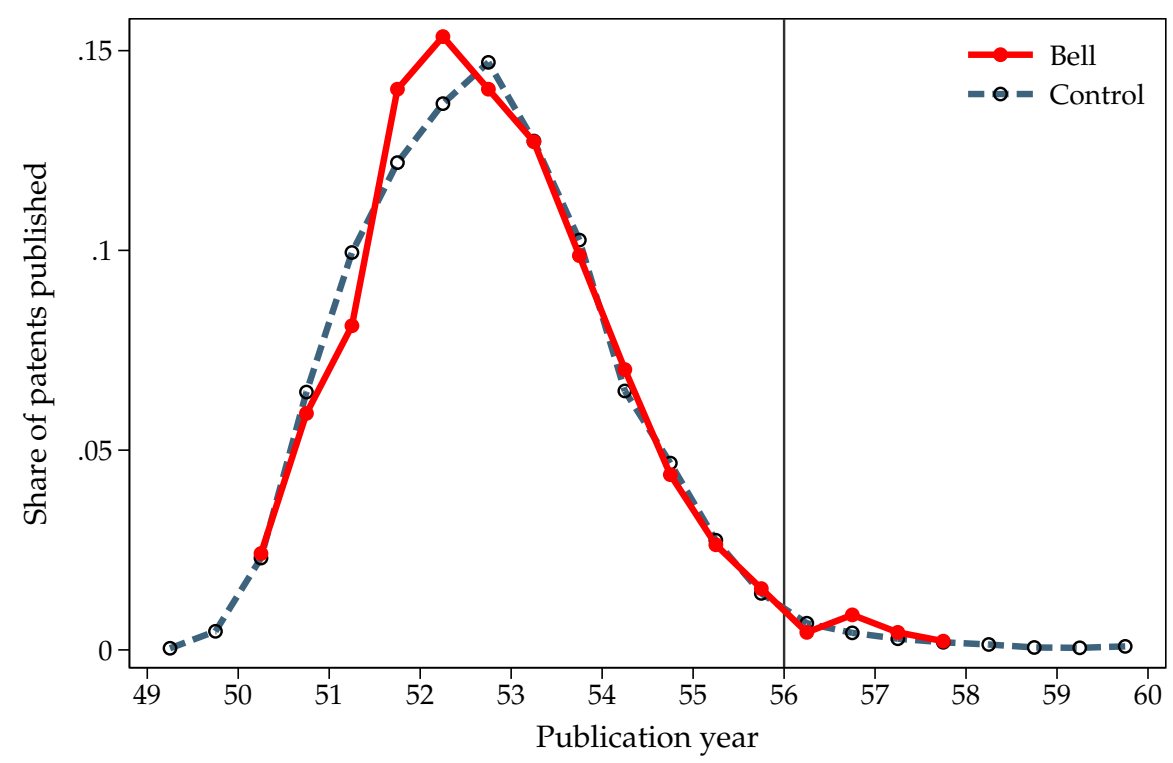

(b) Filing year 1953

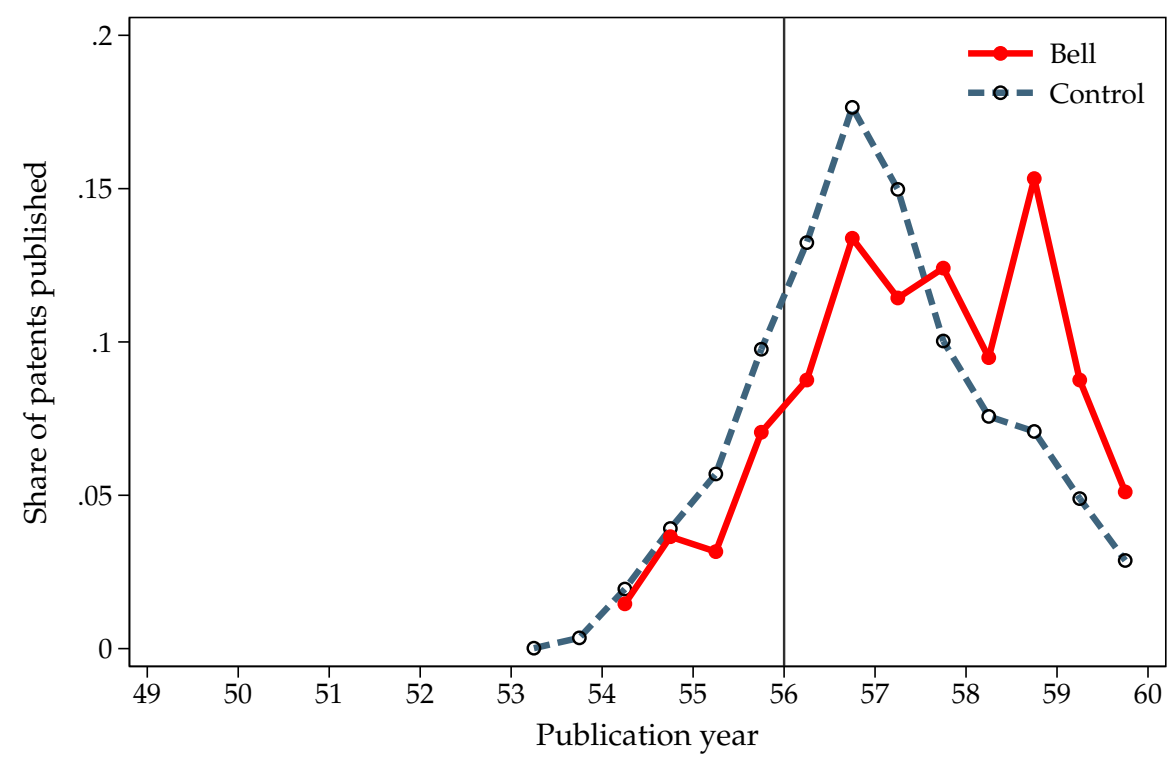

Notes: These figures show the hazard rates for publication of patents that were filed by Bell (solid line) and others (dotted line). Subfigure (a) shows hazard rates for patent applications filed in 1949, subfigure (b) for applications filed in 1953. The data are from the Worldwide Patent Statistical Database (PATSTAT) of the European Patent Office. 
the consent decree (column 2).

Back-of-the-envelope calculations suggest that the additional patents for other companies directly induced by the consent decree had a total value of up to $\$ 5.7$ billion. To calculate this number we use estimates for the average dollar value derived from Kogan et al. (2012) to weigh each citing patent. ${ }^{26}$ According to these estimates, each compulsorily licensed patent created an additional value of $\$ 121,000$ annually in the treatment period (column 3). Assuming homogeneous effects for all 7,820 patents in the treatment group, the consent decree led to around $\$ 5.7$ billion in economic value over six years, between 1954 and 1960. These calculations represent an upper bound because they assume that without the additional citations induced by the consent decree the patent would not have been invented (i.e., that the compulsorily licensed patent was strictly necessary for the citing invention).

The effect is measurable across the quality distribution of patents. We split all patents by the number of citations a patent received in the first five years after publication and present results in columns (4) and (5) of Table 2. We define a high-quality patent as a patent with at least one citation before 1949 and a low-quality patent as a patent with no citations. The effect is stronger for high quality patents, but the effect is also statistically significantly different from zero for low quality patents. The effect is also not exclusively driven by the computer industry, which was just about to start in 1956. In column (6), we report results when dropping all 491 Bell patents classified in the technology subcategories "Computer Hardware and Software", "Computer Peripherals" and "Information Storage" or "Others" (Hall et al., 2001) and find a similar effect. The effect is also not driven by the concurrent consent decrees of IBM in 1956 or RCA in 1958. IBM and RCA were defendants in an antitrust case with compulsory licensing as the outcome. We drop all citations from patents that also cite either the patents of RCA or the patents of IBM and report the results in column (7).

\subsection{Robustness Check: No Increase in Citations by Untreated Companies.}

One concern for the estimation is that the effect of compulsory licensing on subsequent citations might be driven by a shock that increased follow-on innovation to Bell patents and was correlated with the consent decree. For example, the antitrust prosecutors might have chosen to press for compulsory licensing because they expected that there would be many follow-on innovations based on the high quality of the Bell's patents.

To see whether this might have been the case we analyze the citation patterns of unaffected companies to Bell patents and to the control patents. The 1956 consent

\footnotetext{
${ }^{26}$ Kogan et al. (2012) measure the value of a patent using abnormal stock returns around the publishing date of the patent. We use this data to calculate the average dollar value for a patent in each technology class and publication year.
} 


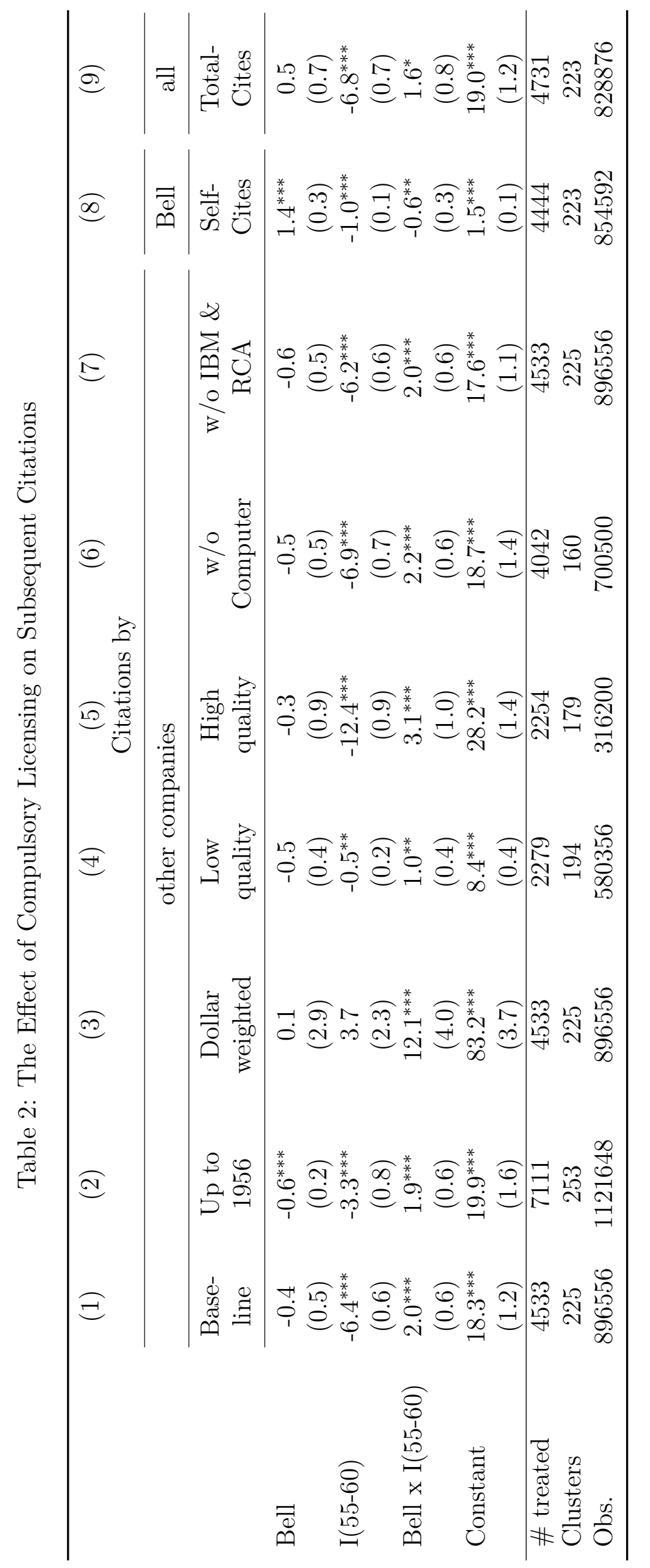

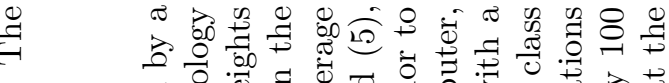

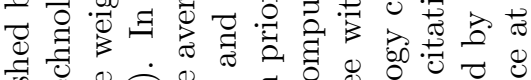

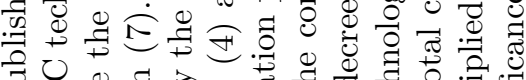

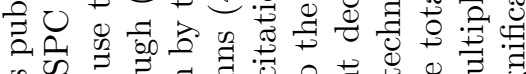
为分 0 。

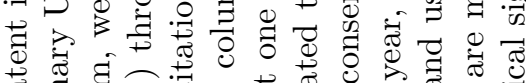

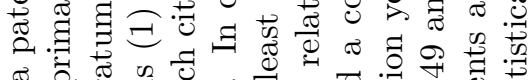

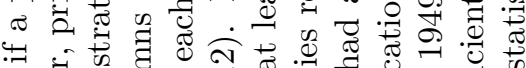

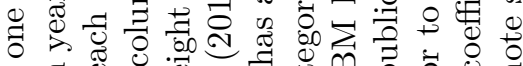

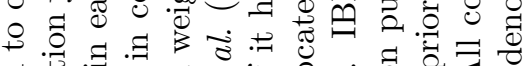

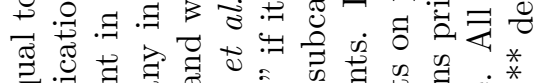
i

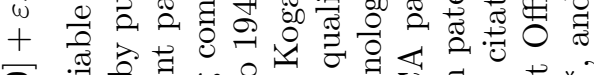

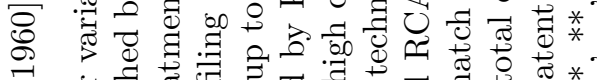

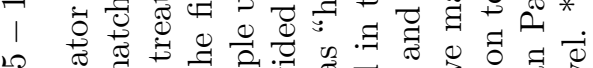
员哥

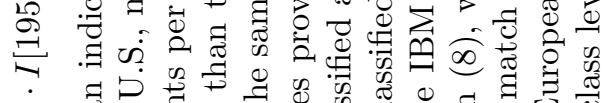

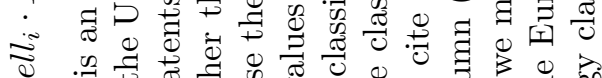

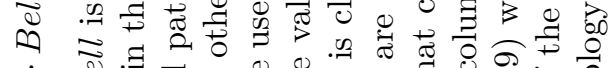
œ $+\dot{0}: \begin{gathered}0 \\ 0\end{gathered}$ ᄋ

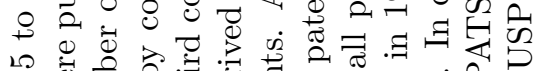

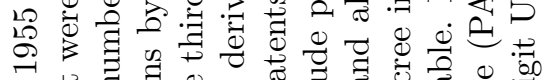

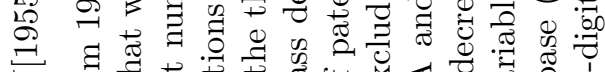

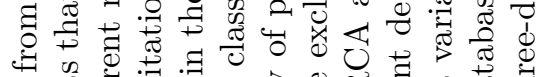

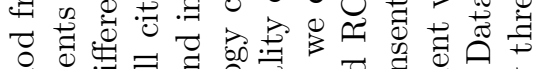
+ 串芯

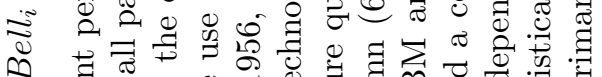

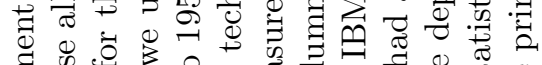

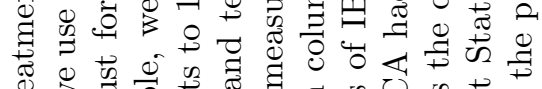

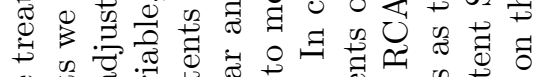
击 范

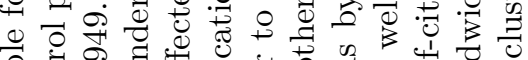

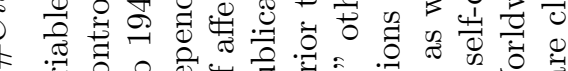

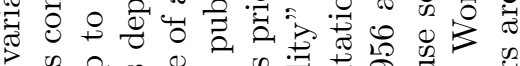

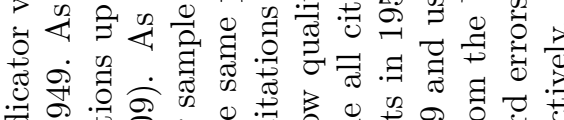

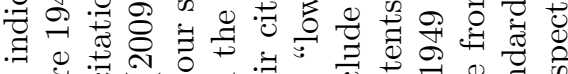
न 붕 की

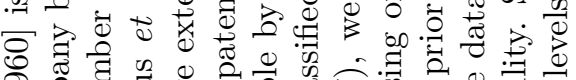
\&

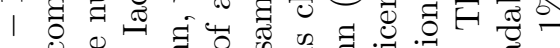

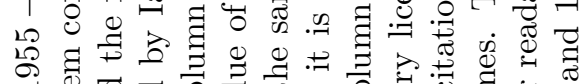

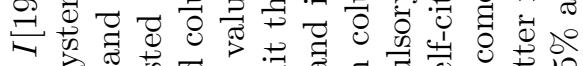

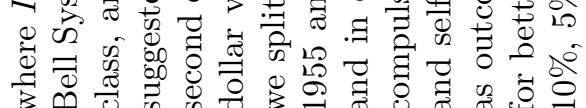


Figure 7: Effect of compulsory licensing on subsequent citations among companies exempt from the consent decree

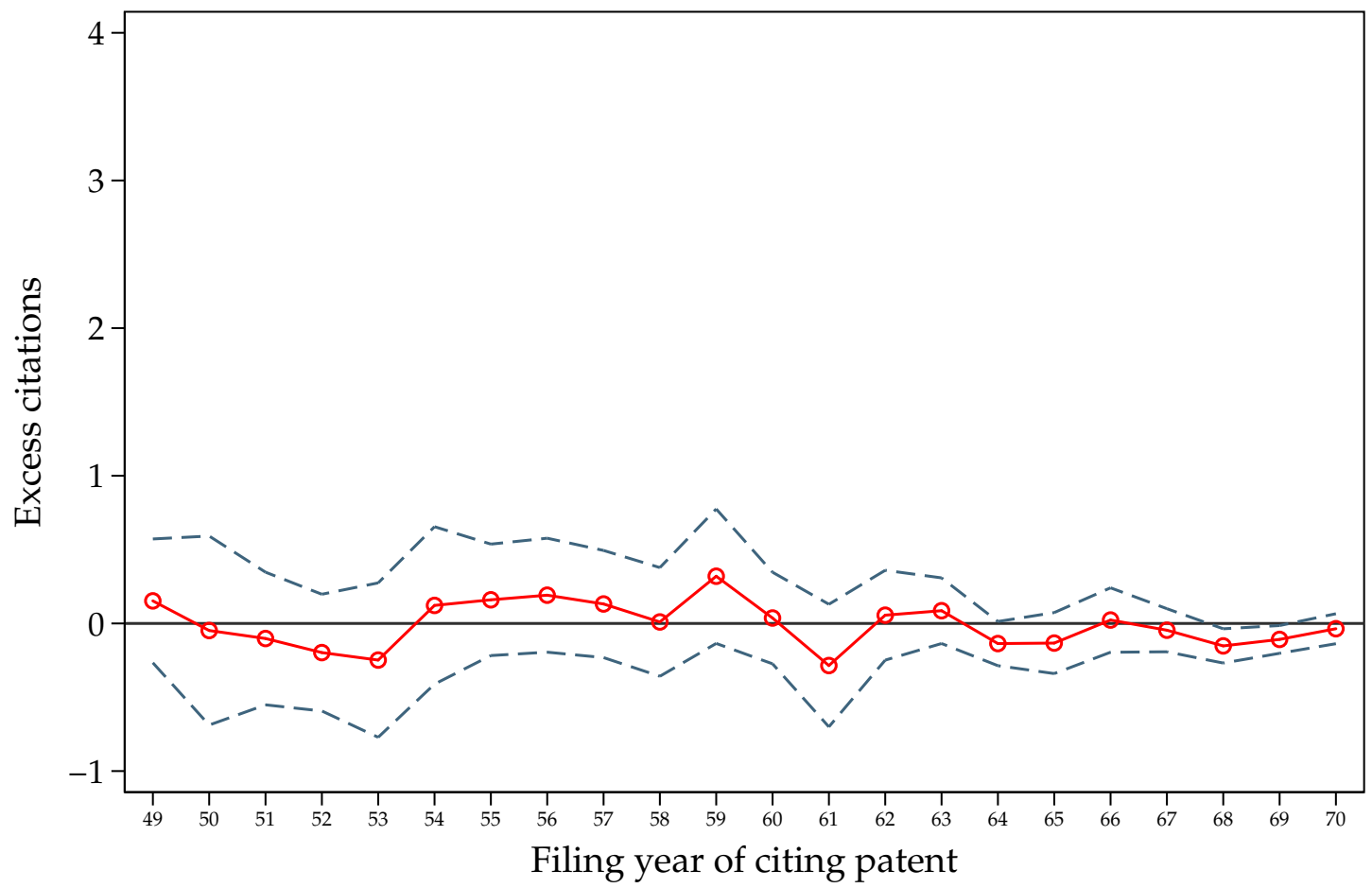

Notes: This graph shows the estimated number of yearly excess citations by General Electric Company, Radio Corporation of America and Westinghouse Electric Corporation, the three companies exempt from the consent decree, and by International Telephone and Telegraph Company, which already had a patent pool in place, of patents affected ("Bell patents") relative to patents with the same publication year, in the same three-digit USPC primary class and with the same number of citations up to 1949. To arrive at these estimates, we regress the number of citations by the unaffected companies in each year on an indicator variable equal to one if the patent under consideration is affected by the consent decree and year fixed effects. The dashed line represents the $90 \%$ confidence bands for the estimated coefficient. To adjust for the different number of control patents per treatment patent in each stratum, we use the weights suggested by Iacus et al. (2009). The data are from the Worldwide Patent Statistical Database (PATSTAT) of the European Patent Office.

decree singled out three companies that were explicitly excluded from the free compulsory licensing of Bell patents: the General Electric Company, Radio Corporation of America, and Westinghouse Electric Corporation. The reason was that these companies already had a general cross-licensing agreement, the "B-2 agreements" dated July 1, 1932. A fourth company, the International Telephone and Telegraph Company (ITT), was also not affected by the decree as it had a patent pool with Bell.

We repeat our baseline analysis but use only the citations of the B-2 companies (including ITT) as the dependent variable and report the results in Figure 7 and column (2) of Table 6 in Appendix B.2 We do not find any effect. This suggests that the consent decree did not change the citation behavior of excluded companies and the measured effects are not due to a common technology shock. As these companies in total make up $12 \%$ of all citations to Bell patents, this null effect is not due to a 
lack of measurability. ${ }^{27}$

A second concern might be that due to the free availability of Bell technology, companies substituted away from other, potentially more expensive technologies. In Appendix B.3 we show the results of additional auxiliary analyses suggesting that the effects are not driven by citation substitution.

Finally, in Appendix B.4 we vary the construction of control groups and show that our results are not driven by the particular choice of matching variables.

\subsection{Robustness Check: The Decrease in Bell's Own Patenting is Lower than the Increase in Patenting by Other Com- panies}

We next examine how Bell reacted to the consent decree. Bell might have reduced its innovation activities by more than other companies increased their innovation activities, such that the net-effect of the consent decree would be negative. To see, whether this is the case we measure whether Bell continued to produce follow-on innovations building on its own patents. ${ }^{28}$ Results are reported in column (8) of Table 2. The number of self-citations shows a decrease of 0.006 self-citations in the years between 1955 and 1960. This decrease is statistically significant, but is not large enough to dominate the increase in citations by other companies. In column (9) we present the effect on total citations, i.e., citations by other companies and self-citations by Bell. We find that total citations increased by 0.016 . This speaks in favor of a net increase in innovation due to the consent decree.

Bell's innovation output in terms of number of patents continued to grow in line with expectations in the years following the consent decree. To show this, we construct a synthetic Bell and compare it with the actual patent output of the Bell System. To construct a synthetic Bell, we first calculate the share of Bell's patents of all patents in each technology subcategory for the years 1946, 1947, and 1948. Then we assume that Bell's growth would have been in line with the growth of other companies that existed before 1949 in these technology subcategories so that Bell would have held its share in each subcategory constant for the following years. Results are presented in Figure 8a. It shows that Bell's patenting is on average smaller than the patenting of the synthetic control, but not by much. ${ }^{29}$

Bell's continued investment in research was in line with the incentives the consent decree and the regulators provided. The consent decree did not significantly alter the

\footnotetext{
${ }^{27}$ We repeat our analysis also for foreign companies, which could also use Bell patents for free but which did not receive technical assistance, and report the results in Table 6, column (3) in Appendix B.2 Similarly, we repeat our analysis for companies that already had a licensing agreement in place and compare them with companies without a licensing agreement (Table 6, columns (4) and (5), Appendix B.2). As expected, we find that the effects are smaller for firms that were less affected by
} 
Figure 8: Innovation and R\&D in the Bell System After the Consent Decree

(a) Patenting Over Time: Bell system and Synthetic Bell

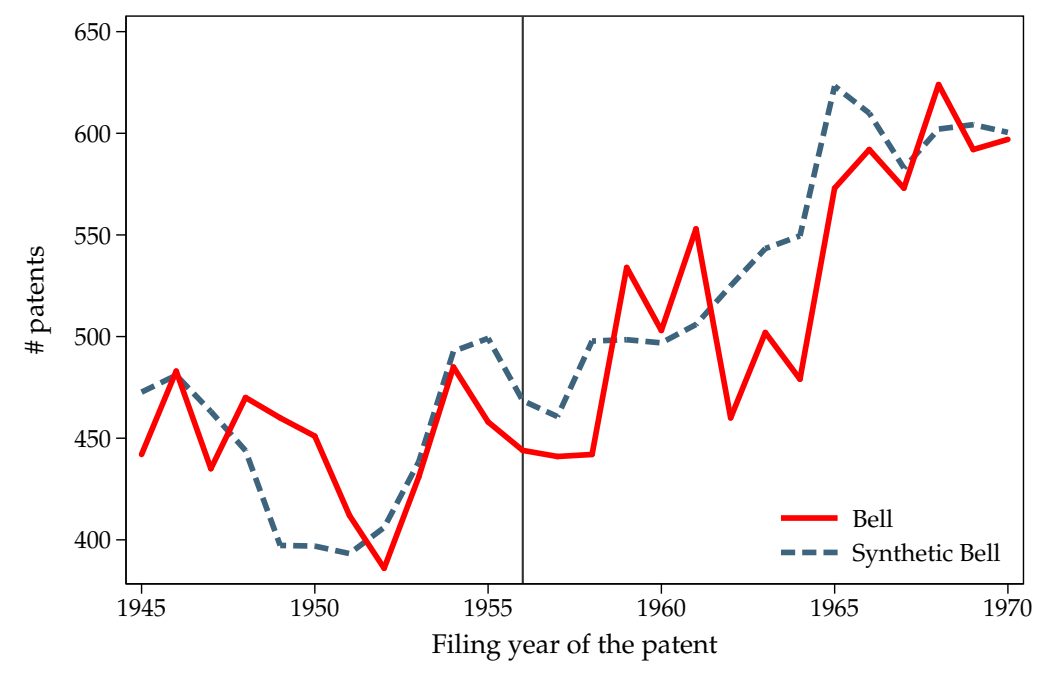

(b) R\&D Spending by AT\&T

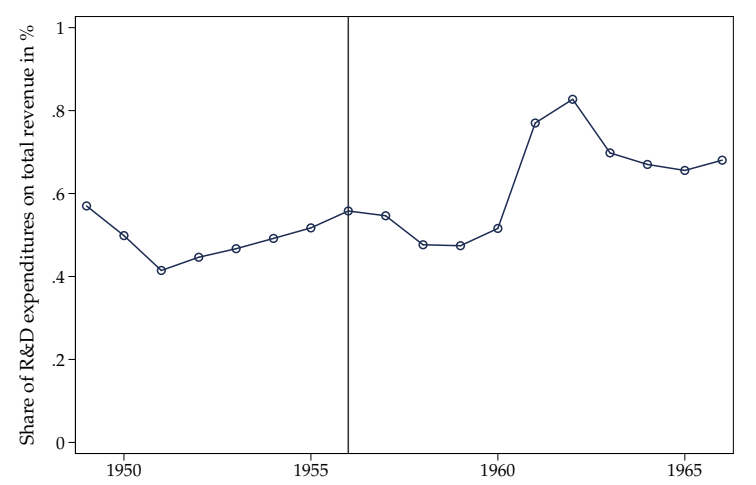

(c) Share of Communication Patents

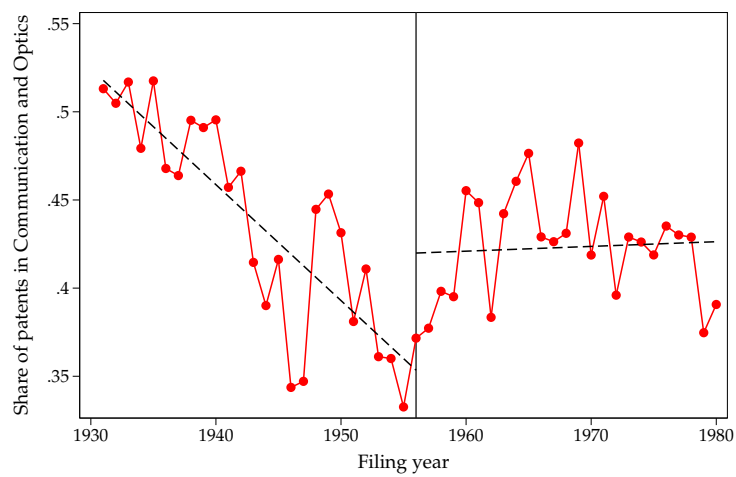

Notes: Subfigure (a) shows the total number of patents filed by the Bell System compared to a synthetic Bell. To construct the synthetic Bell, we calculate the share Bell's patents had in each 2digit technology subcategory relative to all patents of companies that had at least one patent before 1949. We then assume that in the absence of the consent decree, Bell's patenting would have grown in each subcategory at the same pace as the patenting of all other companies. As a consequence, Bell's share in each technology subcategory is held constant. In a last step, we add the number of patents up to a yearly sum. Subfigure (b) shows the ratio of R\&D expenditures relative to total R\&D of American Telephone \& Telegraph. The data are from the annual reports of AT\&T. Subfigure (c) shows the share of patents related to communication relative to all patents filed by Bell. We define a patent as related to communication if the most likely application is in the production of telecommunications equipment (SIC 3661). In Appendix B.6 we show the change in direction using NBER subcategories. The patent data are from the Worldwide Patent Statistical Database (PATSTAT) of the European Patent Office. 
profitability of new patents. The consent decree mandated that Bell could demand "reasonable" licensing fees for all patents published after January 1956. The reasonable royalty rates Bell charged were not much different compared to the pre-decree royalties (Antitrust Subcommittee, 1959, p.111). The only difference was that Bell had to give a license to any applicant.

Bell also had little incentive to reduce investment in $R \& D$ because the Bell System was subject to a rate of return regulation following the Communications Act of 1934 . According to annual reports, AT\&T had a stable ratio of R\&D to operating revenue of $0.5 \%$ from 1949 to 1960 (Figure 8b). ${ }^{30}$ For the entire Bell System, the share of R\&D to total turnover stayed almost constant at 2\%-3\% from 1966 to 1982 (Noll, 1987). However, the absolute level of R\&D effort increased as the Bell System grew. Operating revenues increased from $\$ 3.2$ billion in 1950 to $\$ 5.3$ billion in 1955 , to $\$ 7.3$ billion in 1960 and to $\$ 11$ billion in 1965, while the staff at Bell Labs grew from 6,000 in 1950, to 10,000 in 1955, to 12,000 in 1960 and 15,000 in 1965 (Temin and Galambos, 1987).

But even if the consent decree offered no incentive for Bell to downsize, it offered incentives for Bell to redirect its research budget towards applications in the telecommunications field. Prior to the consent decree, Bell could expand to other businesses. Afterward, Bell's future was bound to common carrier telecommunications. The company correspondingly refocused its research program on its core business and increased its share of patents in fields related to the production of telecommunications equipment (Figure 8c).

These results are consistent with the study of Galasso and Schankerman (2015a) on patent invalidations. They show that large companies on average do not reduce followon innovations significantly if they lose a patent due to litigation. The only exception is if the large company loses a patent outside of its core-fields. Then it reduces innovation in the field of the patent under consideration and reacts by redirecting future innovation to a different but related field.

\footnotetext{
the consent decree.

${ }^{28}$ Self-citations are a measure for how much a company develops its own patents further (Akcigit and Kerr, 2010; Galasso and Schankerman, 2015a).

${ }^{29}$ In Figure 17 in the Appendix B.5 we compare the patenting output of Bell with other control companies and find that Bell's patent growth is in line - but at the lower end - of similar companies. The only exception is the growth of General Electric which is much larger, highlighting the problem of constructing a counterfactual for a single company.

${ }^{30}$ We do not know whether the consolidated balance sheet also includes the Bell Laboratories and Western Electric. It seems that at least some parts of the Bell System are not consolidated in the annual reports of AT\&T.
} 


\subsection{Mechanism: Increase in Citations is Driven by Start-ups.}

We next examine which type of company increases innovation after the compulsory licensing and report the results in Table 3. We split citations by the type of the citing assignee. An assignee is either a company or an individual inventor; an assignee is defined as young and small if its first patent was filed less than 10 years before it cited the Bell patent and if it had less than 10 patents before 1949. ${ }^{31}$ We first use the number of citations from young and small assignees as the dependent variable and report the results in column (2). We then use the citations of all other assignees that are not young and small and report the results in column (3). In column (4) we look explicitly at small and young assignees that are companies ("start-ups"), leaving out individual inventors. ${ }^{32}$

We find that the increase in follow-on innovation is predominantly driven by young and small companies entering the market and by individual inventors. Young and small assignees increase their citations after 1955 by an average of 0.014 citations (32\%) while all others increase their citations by 0.006 (6\%) on average. Around $70 \%$ of the overall increase comes from young and small assignees, but they are responsible for only onethird of all citations to Bell patents (columns (2) and (3) in Table 3). ${ }^{33}$ Among the small and young assignees, start-ups experience a particularly strong increase: they account for $50 \%$ of the total increase in citations although they are responsible for only $18 \%$ of all citations (column 4 ).

These results suggest that patents act as a barrier of entry for start-ups and prevent their follow-on innovation. They provide support for the hypothesis that the consent decree reduced potential bargaining failures. Several prior studies suggest that small firms might not have large enough patent portfolios to resolve disputes or to strike cross-licensing agreements (Lanjouw and Schankerman, 2004; Galasso, 2012; Galasso and Schankerman, 2015b). As cross-licensing was a priority in the licensing strategy of Bell prior to the consent decree, a small patent portfolio might have been a significant handicap for small inventors seeking a license from Bell (Antitrust Subcommittee, 1958, p. 2685).

One potential concern might be that the observed increase of citations by young and small companies was driven not by the consent decree itself but by other changes at Bell

\footnotetext{
${ }^{31}$ In Appendix B.7 we use different definitions for young and small companies and find that the effect is mainly driven by companies that file their first patent.

${ }^{32}$ We identify companies as all assignees that are never inventors. Our results are robust to defining companies as having Inc., Corp., Co. or similar abbreviations in their name.

${ }^{33}$ Young and small assignees are responsible for an increase of 0.014 citations (column 2). This is $70 \%$ of the total increase of 0.02 (column 1). It is also an increase of around $32 \%$ relative to what we would have expected without a consent decree. According to the estimates a Bell patent should have received 0.044 citations ( 0.068 is the constant, the Bell effect is -0.008 , and the average decrease in citations in the post treatment period is -0.016$)$ but did receive 0.058 citations ( 0.044 baseline effect +0.014 treatment effect).
} 


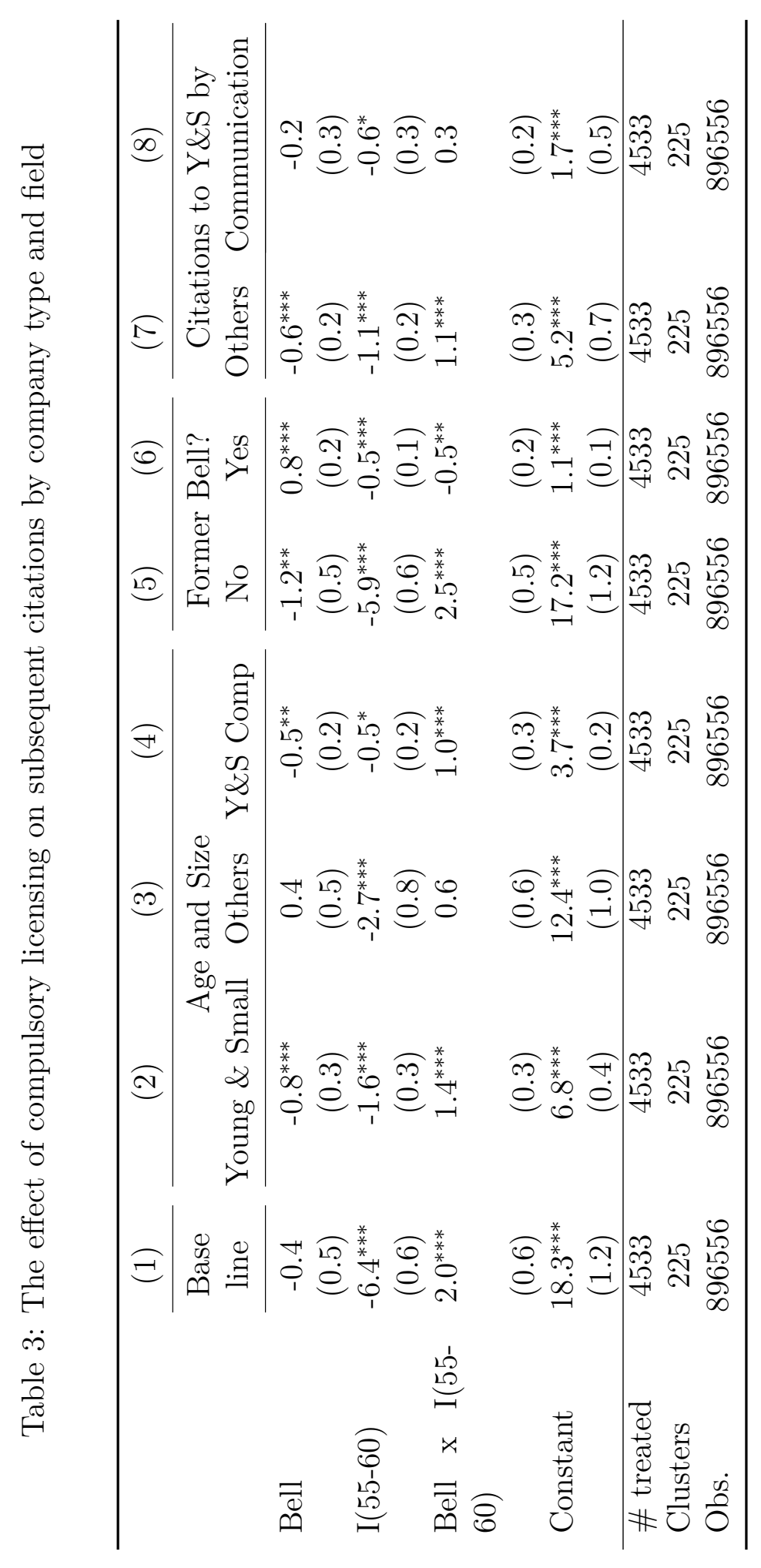

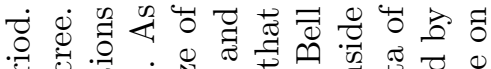

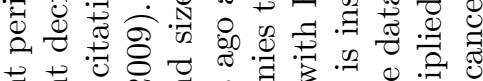

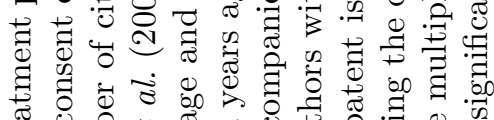

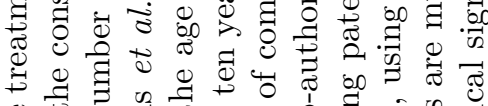

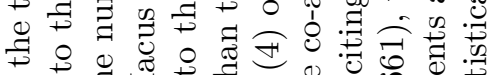

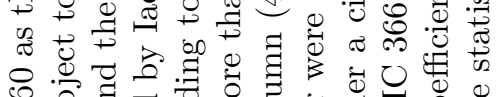

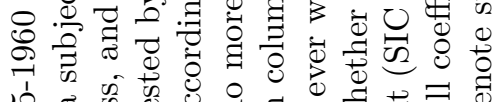

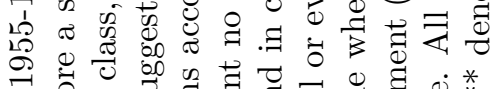
ت

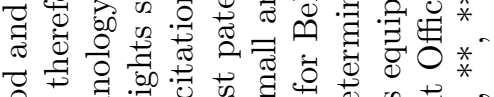

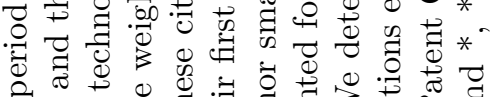

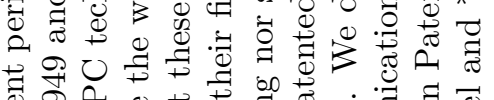

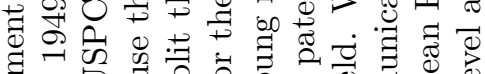

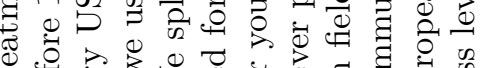

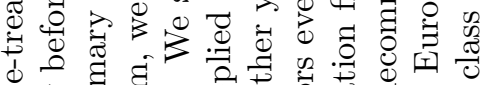

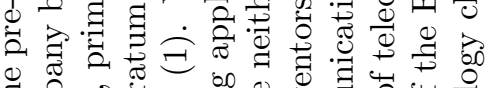

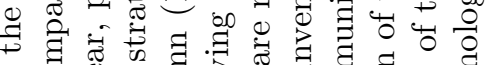

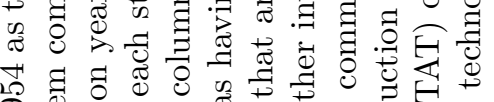

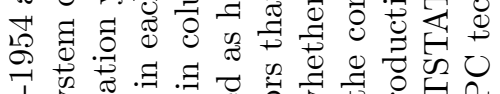

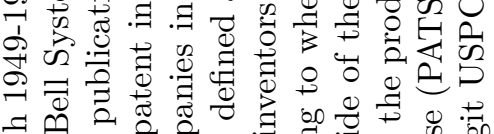

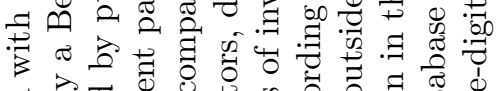

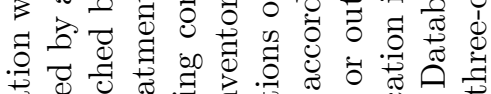

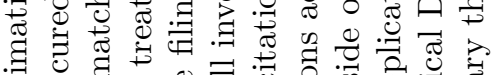

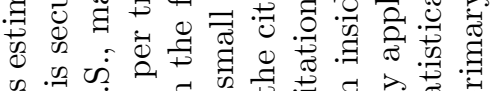

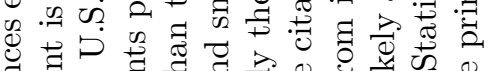

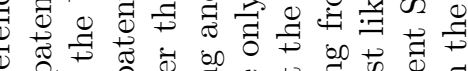

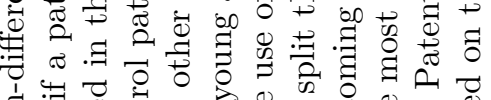

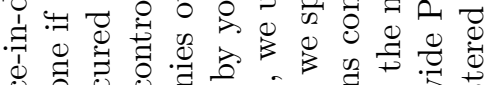

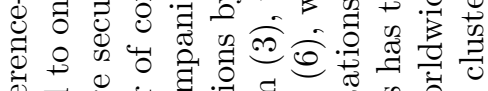

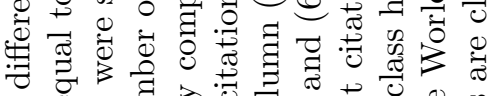

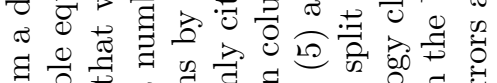

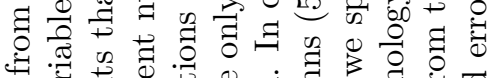

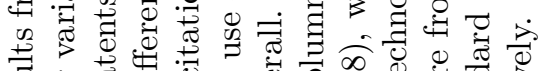

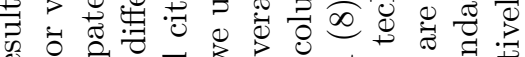

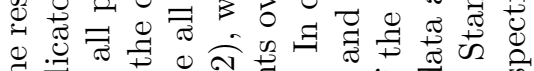

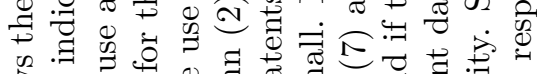

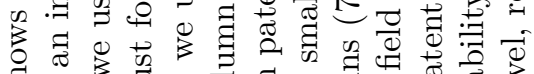

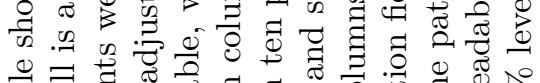

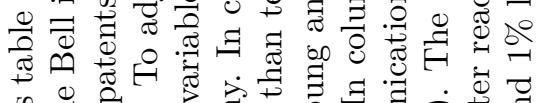
架吅

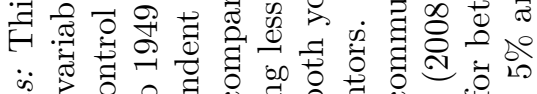

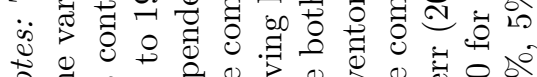

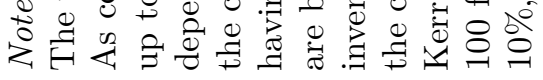


Laboratories. Historical accounts suggest that there was an exodus of important Bell researchers around the time of the consent decree. For example, in 1953 Gordon Teal, inventor of a method to improve transistor performance, joined the then small Texas Instruments Inc. Similarly, William Shockley, one of the inventors of the transistor, left Bell in 1956 to found Shockley Semiconductors Laboratory.

To show that this is not the case, we separately look at patent citations by people who were at some point associated with Bell, but later patented for a different company, including their co-inventors, and compare with citations by all remaining unrelated inventors. In our data, there are 4,477 former Bell employees with 28,569 patents. These people have in total 12,068 co-inventors who were never active at Bell and who filed 87,148 patents in total. The results are reported in columns (5) and (6) of Table 3. We find a positive effect on the citations of unrelated inventors and a negative effect on the citations of related inventors. ${ }^{34}$ This pattern does not suggest that the increase in follow-on innovation was driven by former Bell employees. However, the results do suggest that the Bell inventors had preferential access to Bell technology prior to the consent decree and that there was a strong increase from unrelated inventors afterwards.

\section{Compulsory Licensing did not End Foreclosure in the Market for Telecommunications Equipment}

The aim of the consent decree was to end foreclosure in the market for telecommunications equipment. According to the antitrust lawsuit, Bell was closing the market to all other buyers and sellers of telecommunications equipment by using exclusive contracts between Western Electric and the Bell operating companies and by refusing to license patents to competitors. In markets outside of the telecommunications industry Bell was active only as a supplier of technology but was not an active market participant.

Market foreclosure is thought to have a negative effect on the innovation activities of the companies that are foreclosed (Baker, 2012; Wu, 2012). The argument is that foreclosed companies cannot earn profits by selling their improved products directly to consumers. The only option they have is to sell their innovations to other companies. ${ }^{35}$ Thus, foreclosed companies have lower incentives for innovation than companies with access to a customer base.

In this section we compare the innovation effects of compulsory licensing inside and outside of the telecommunications industry to infer whether market foreclosure

\footnotetext{
${ }^{34}$ The estimated yearly coefficients for excess citations of former Bell inventors and of unrelated inventors are available from the authors upon request.

${ }^{35}$ Such a market for ideas exists only in special circumstances (Gans et al., 2002; Gans and Stern, 2003; Gans et al., 2008).
} 
Figure 9: Excess Citations by Patents with Varying Likelihood of Being used in Production of Communication Equipment

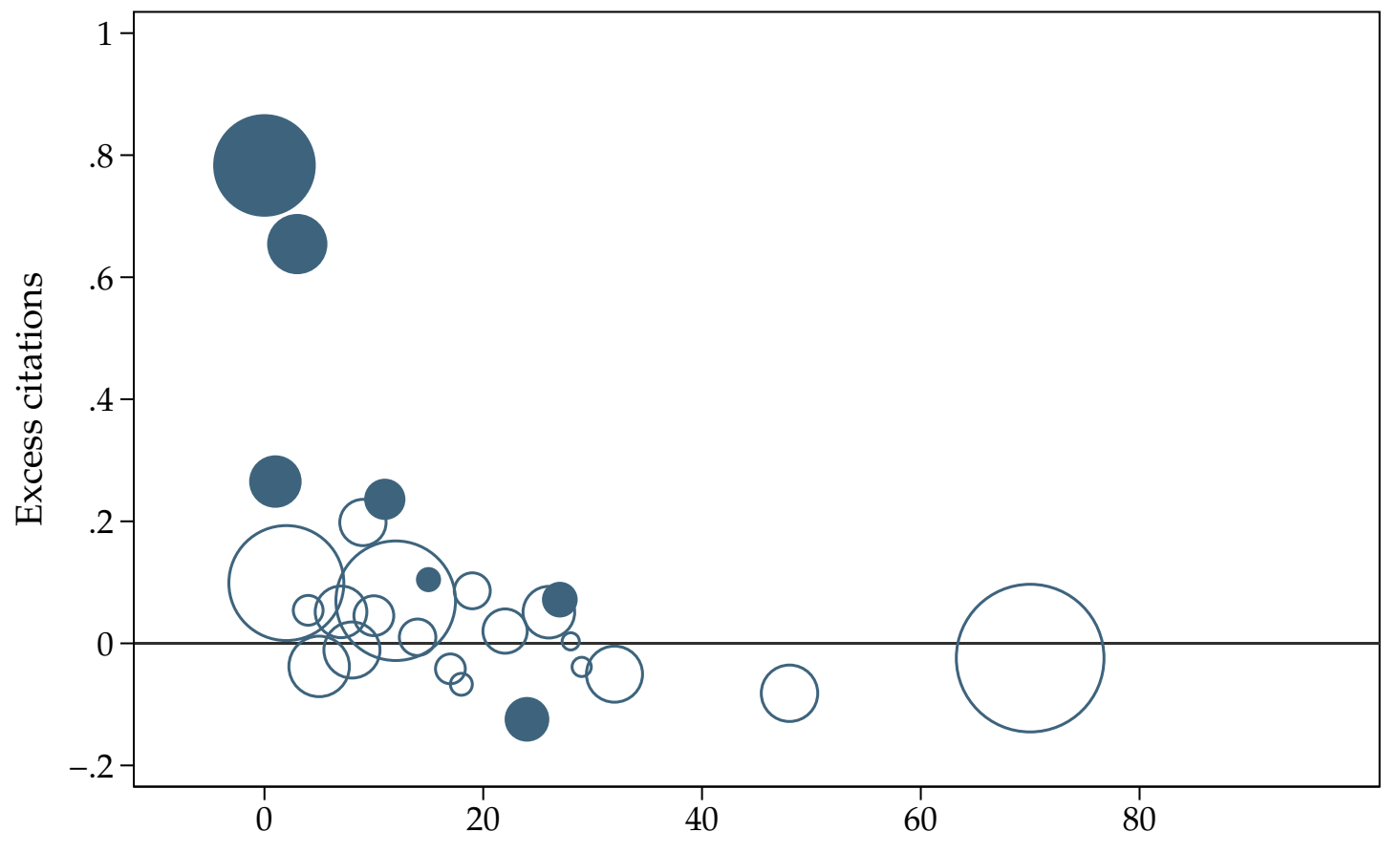

$\%$ used in production of telecommunications equipment SIC 3661

Notes: This figure shows results from a difference-in-differences estimation of the impact of the consent decree on follow-on patent citations with 1949-1954 as the pre-treatment period and 1955-1960 as the treatment period, controlling for year fixed effects. We estimate Equation 2 and report $\beta_{3}$ separately, using as dependent variables citations from patents with a different relevance for the production of telecommunication equipment (SIC 3661 - "Telephone and Telegraph Apparatus"). Relevance is measured by the likelihood that a patent is used in industry SIC 3661 using the data of Kerr (2008). The size of the circle signifies the number of Bell patents in a technology and a solid circle implies that the coefficient is significant at the $10 \%$ level. The data are from the Worldwide Patent Statistical Database (PATSTAT) of the European Patent Office.

is harmful for innovation and whether compulsory licensing is effective in ending it. If compulsory licensing increases innovation in the same way in all industries, then any difference between the two competitive settings must be due to market foreclosure in the telecommunications industry. If market foreclosure reduces innovation as argued above and if compulsory licensing was effective in ending it, we should see a stronger increase in follow-on innovations in the telecommunications industry than in other industries. In contrast, if compulsory licensing was ineffective in ending market foreclosure, we should find a smaller effect. If market foreclosure has no effect on innovation, we should find similar effects in all industries.

To compare the innovation effects within telecommunications and outside we first need to characterize each citing patent by its closeness to the market for telecommunications equipment. To do this, we use the concordance of Kerr (2008) that gives us the probability for each USPC technology class that a patent in this technology class 
is used in the production of telecommunications equipment (SIC 3661). We interpret this probability as a measure of closeness to telecommunications. We then assign this probability to each citing patent according to its technology class and sum up the citations for each level of likelihood to construct a different dependent variable for each level of closeness, 26 altogether. In a last step, we repeat our main regression for each level of closeness. We can thus estimate how much the consent decree increased citations in markets that are close to the production of telecommunications equipment and in markets unrelated to it.

In Figure 9 we show the average treatment effects estimated with our baseline model in equation 2 for different levels of closeness to the production of telecommunications equipment. We find a strong negative relation between the closeness to telecommunications and excess citations. Almost all excess citations come from patents that have nothing to do with telecommunications. We conclude from this that follow-on innovation in telecommunications was not influenced by compulsory licensing. Under the assumption that compulsory licensing affects innovation similarly in all industries this result supports the argument that market foreclosure has a chilling effect on innovation and indicates that compulsory licensing was ineffective in solving it.

Next, we use Kerr's data to assign each citing patent to the industry in which it is most likely used and repeat the baseline regression with citations from patents in different industries. The results are shown in Figure 10. Almost all additional citations are from patents with the most likely application outside of the industry "Telephones and Telegraphs" (SIC 3661). A large part of the effect is driven by unrelated industries such as "Measuring and Controlling," "Audio and Video Equipment" or "Motor Vehicles." 36 These results support the notion that market foreclosure is harmful for innovation and that compulsory licensing is ineffective as a remedy. ${ }^{37}$

Foreclosure seems to be particular harmful for start-up innovation. In columns (7) and (8) of Table 3 we show that small and young companies increased their citations only outside the field of telecommunications, but not inside. ${ }^{38}$ As a large part of the effect in the full sample was driven by small and young companies, this suggests that also start-ups react strongly to market foreclosure. In fields outside of telecommunications, compulsory licensing fostered innovation by small and young companies since Bell as the supplier of technology did not control product markets through vertical

\footnotetext{
${ }^{36}$ In the Appendix C.1 we repeat the analysis using NBER technology subcategories to classifiy the citing patent. The results are the same.

${ }^{37}$ Another explanation for our null result in the telecommunications market would be that there was a lack of innovation potential in the telecommunication sector after 1956. To rule out this hypothetical possibility we compare the development of patents in the telecommunications sector. Results are reported in Figure 21 in Appendix C.2 They show that the number of citations to Bell's telecommunications patents had a similar trend as patents outside of telecommunications and that the number of Bell's newly filed telecommunications patents shows no signs of abating after the consent decree.

${ }^{38}$ We use the most likely SIC code to determine the field of the citing patent.
} 
Figure 10: Excess Citations by Patents According to the Most Likely SIC Industry Classification

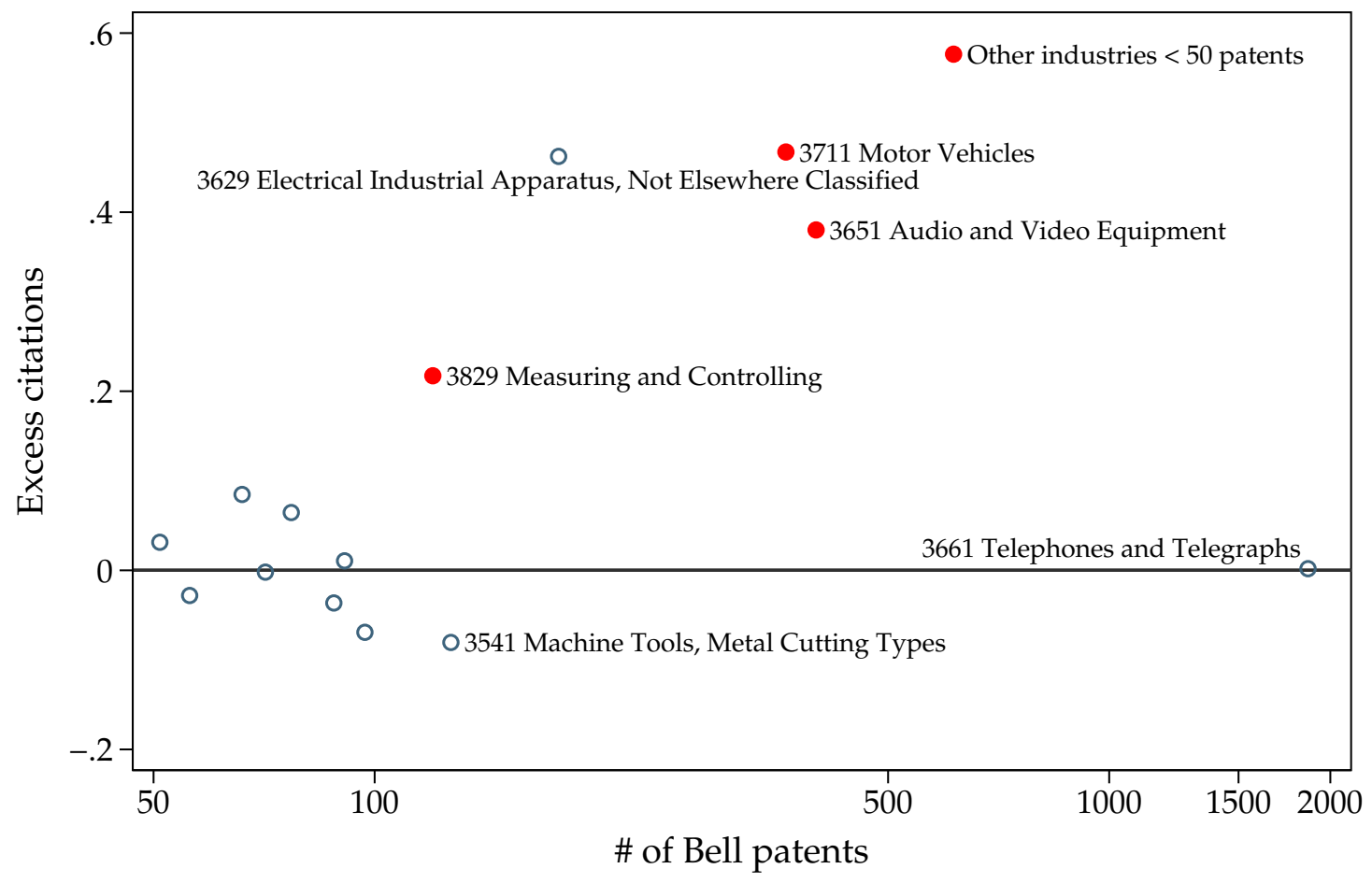

Notes: This figure shows results from a difference-in-differences estimation of the impact of the consent decree on follow-on innovation with 1949-1954 as the pre-treatment period and 1955-1960 as the treatment period, controlling for year fixed effects. As the dependent variable, we use all citations by companies other than the filing companies classified by the most likely SIC classification of the citing patent. As control patents, we use all patents that were published in the U.S. matched by publication year, primary USPC technology class, and the number of citations up to 1949. To classify a patent by its most likely industry, we use the data of Kerr (2008). We assign to each USPC class the most likely four-digit SIC industry in which it is used. A solid circle indicates that a coefficient is significant at the $10 \%$ level. The data are from the Worldwide Patent Statistical Database (PATSTAT) of the European Patent Office. 
integration or via exclusive contracts.

Our results suggest that market foreclosure stifles innovation and that compulsory licensing is not sufficient to foster innovation without supporting structural remedies. This confirms the general perception at the time of the lawsuit. Both the public and antitrust officials were aware that because of Bell's persistent monopoly compulsory licensing would only help companies outside the telecommunications field. A witness in the Congressional hearings put it succinctly: "while patents are made available to independent equipment manufacturers, no market for telephone equipment is supplied (...). It is rather a useless thing to be permitted to manufacture under patent if there is no market in which you can sell the product on which the patent is based." The Antitrust Subcommittee concluded that "The patent and technical information requirement have efficacy only so far as they permit independent manufacturers to avail themselves of patents in fields that are unrelated to the common carrier communication business carried on by the Bell System companies, and nothing more." On May 4, 1954, presiding Judge Stanley N. Barnes suggested that compulsory licensing policy for reasonable rates is "only good window dressing" but would do no good because Western Electric had already "achieved an exclusive position (...) and liberal licensing would not permit competitors to catch up" in the telecommunications business (Antitrust Subcommittee, 1959, pp. 108).

In the years after the consent decree, the Bell System faced repeated allegations of exclusionary behavior. By the 1960s and 1970s, a range of new firms were eager to enter the telecommunications market but Bell implemented measures to make it expensive or impossible (Wu, 2012). This led to a number of regulatory actions, for example forcing interconnections of Bell's telephone system to the entering competitors MCI in 1971 which provided long distance services using microwave towers (Temin and Galambos, 1987; Gertner, 2012, p. 272). Eventually, the continued monopolization of the telecommunications market by Bell resulted in the 1974 antitrust lawsuits. The lawsuit mirrored almost scene by scene the case of 1949. Again Bell was charged with excluding competitors from the market of telecommunications equipment. Again, the Department of Defense intervened on the grounds of national defense. But the Reagan administration was not as accommodating as the Eisenhower administration had been and the Department of Justice was keen on going after Bell. The case ended with the break-up of the Bell System in 1983, opening up the market for telecommunications equipment for competition. 


\section{The Consent Decree Increased U.S. Innovation in the Long Run}

The historical set-up of the Bell case gives us the opportunity to look also at the longrun innovation effects of a consent decree. In the previous section we have shown that the increase in follow-on citations is measurable for the first five years. This raises the question how lasting the impact of a large-scale intervention in patent rights really is. To answer this question we study the long-run impact of the case against Bell on the patent activities of firms patenting in the U.S. More specifically, we examine the increase in the total number of patents in a USPC technology subclass with a compulsorily licensed Bell patent relative to a subclass without. We employ the following empirical model

$$
\text { \#Patents } s_{s, t}=\beta_{t} \cdot I(\text { Bell }>0)_{s}+\text { Controls }+\varepsilon_{s, t}
$$

where the outcome variable is the total number of patents in a technology subclass $s$ (Moser and Voena, 2012; Moser et al., 2014). The treatment variable equals one if there is at least one compulsorily licensed patent in the technology subclass. As controls, we use USPC class-year fixed effects. ${ }^{39}$ Our sample consists of 235 classes with 6,276 subclasses of which 1,209 are treated. ${ }^{40}$

In Figure 11a we plot the number of excess patents for all patent classes. We leave out patents by Bell to focus on patenting of other companies. Starting in 1953, the number of patents in technology classes where Bell patents were compulsorily licensed increased relative to subclasses without Bell patents, and it continued to do so beyond 1960, when the last Bell patents affected by the consent decree expired. This suggests that the consent decree increased U.S. innovation in the long run.

To quantify the effect we next estimate the average yearly effect of the consent decree on the total number of patent applications for the time period 1949-1960. We employ the following difference-in-differences model:

$$
\text { \#Patents } s_{s, t}=\beta_{1} \cdot I(\text { Bell }>0)_{s}+\beta_{2} \cdot I(\text { Bell }>0)_{s} \cdot I[1955-1960]+\text { Controls }+\varepsilon_{s, t}
$$

where $I(\text { Bell }>0)_{s}$ is 1 if Bell has a patent in the subcategory $s$. As controls we use class-year fixed effects.

The coefficients are reported in Table 4 . In the first five years alone, patent applications increased by 2.5 patent applications in treated classes (column 1). This is an increase of around $24.5 \% .{ }^{41}$ Furthermore, patent applications by new companies enter-

\footnotetext{
${ }^{39}$ To follow the literature we use USPC technology classes here and not SIC classes.

${ }^{40}$ We exclude subclasses that did not have any patents at all before 1956 and we include only patent classes that contain subclasses that were treated and subclasses that were not.

${ }^{41}$ Untreated subclasses have on average 2.17 patent applications in the the pre-treatment period.
} 
Figure 11: Impact of the Consent Decree in the Long Run

(a) Annual Treatment Effects on the Number of Patent Applications

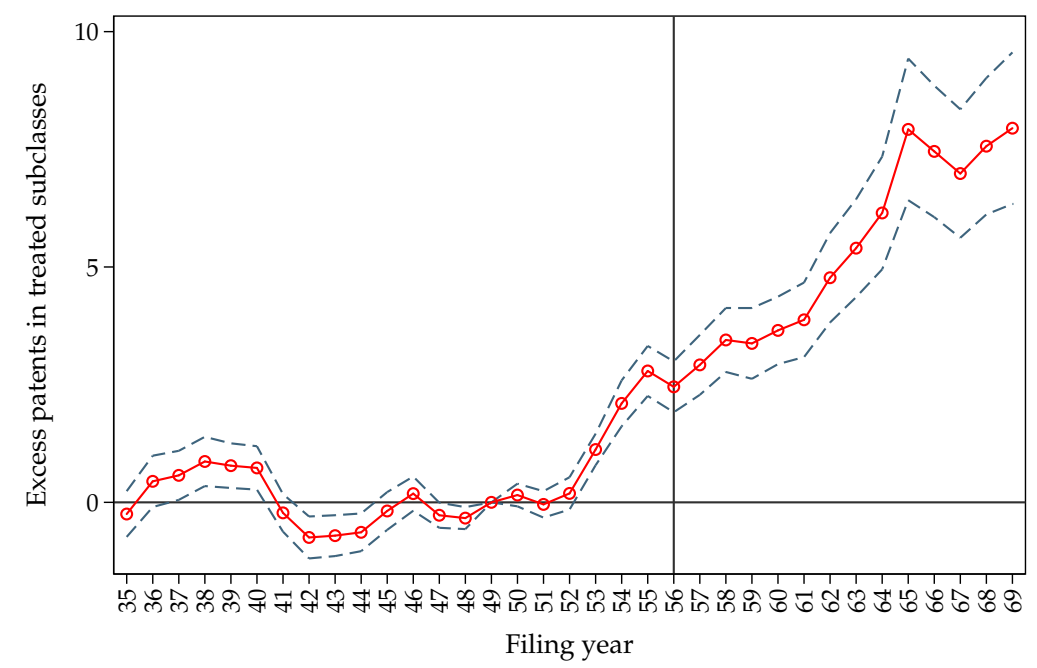

(b) Excess Patents sorted by Likelihood of Being Used in the Production of Telecommunications Equipment

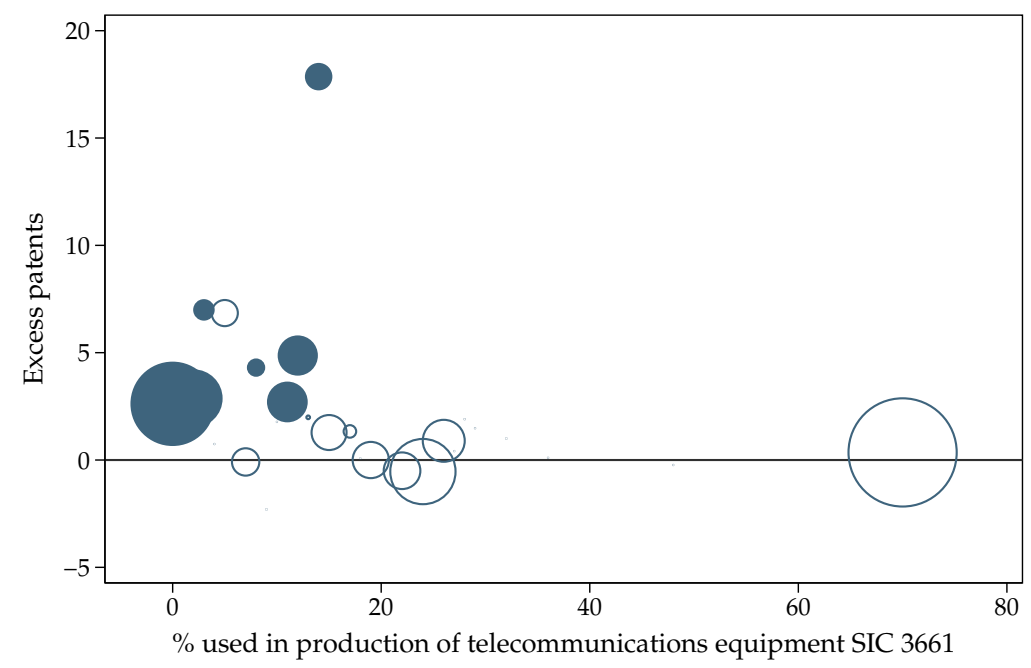

Notes: The dependent variable is the number of patent applications per (aggregated) subclass per year. A subclass is treated if it contains at least one Bell patent that was subject to compulsory licensing. Subfigure (a) shows annual treatment effects $\beta_{t}$ estimated with Equation 3 for all patent classes. Standard errors are clustered at the class level. Subfigure (b) shows the average increase in the number of patents $\beta_{2}$ estimated with Equation 4 for patent classes with varying likelihood of being used in the production of telecommunications equipment. To determine the likelihood that a patent is used in industry SIC 3661 we use the data of Kerr (2008). The size of the circle signifies the number of Bell patents in a technology and a solid circle implies that the coefficient is significant on the $10 \%$ level. The data are from from the Worldwide Patent Statistical Database (PATSTAT) of the European Patent Office. 


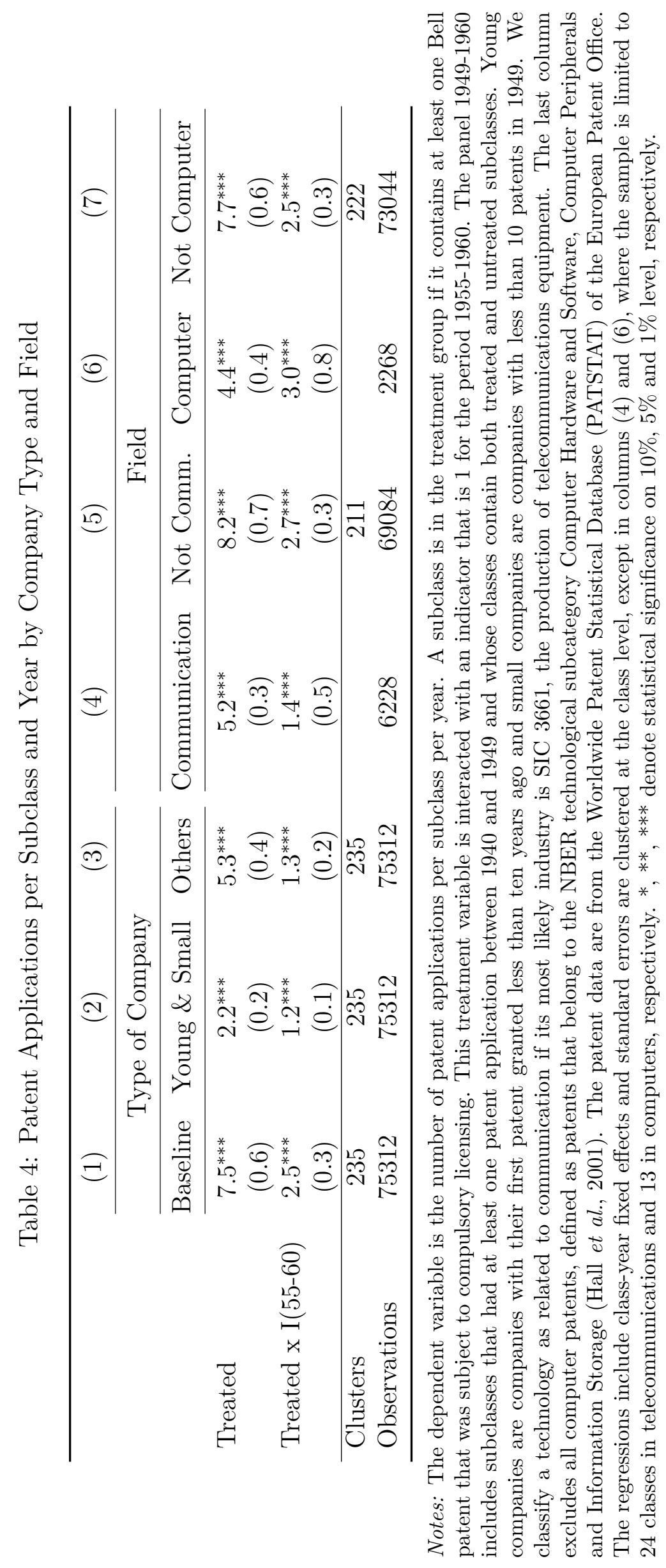


ing the market increased relatively more than patent applications by other companies (columns 2 and 3$).{ }^{42}$

The increase appears to be stronger outside of telecommunications technologies (column 4 and 5). In Figure 11b we plot the average treatment effects estimated with Equation 4 for different levels of closeness to the production of telecommunications equipment. Again the effects are weak for technologies closely related to the production of telecommunications equipment and strong for unrelated technologies. This again suggests that the fields in which Bell continued to operate experienced slower technological progress than markets where entry of start-ups was possible. ${ }^{43}$

Figure 11a shows that the increase in patenting begins in 1953, two years before the increase in citations to Bell patents. In 1953, Bell's most important invention, the transistor, became available for licensing, spurring the creation of the computer industry. To make sure that the entire increase is not driven by this one exceptional invention, we analyze computer and non-computer patents separately and report the results in columns (6) and (7) of Table 4. The effect is stronger for the computer patents, but the increase in patenting is also significant without any computer patent.

Thus, overall we find that the consent decree led to a long-lasting increase in the scale of innovation mainly outside the telecommunications field. This is consistent with the theoretical argument by Acemoglu and Akcigit who build on the the step-by-step innovation model of Aghion et al. (2001) to analyse the effects of compulsory licensing on innovation (Acemoglu and Akcigit, 2012). They consider the case where all current and future patents in the economy are compulsorily licensed for a positive price and identify two main effects. On the one hand, compulsory licensing helps technological laggards to catch up and brings more industries to a state of intense competition. This 'composition effect' increases innovation, because companies in industries with intense competition invest more in $\mathrm{R} \& \mathrm{D}$ in order to become the industry leader. On the other hands, compulsory licensing reduces the time a technology leader keeps its profitable position. This 'disincentive effect' reduces the innovation and growth in the economy.

In our case, compulsory licensing was selectively applied to one company that did not participate in any market other than the telecommunications market. This enabled many new companies to enter markets with state-of-the art technology and to compete for the industry leadership with full patent protection of future inventions intact (Holbrook et al., 2000). Thus in all industries but the telecommunications

In these subclasses the number of patent applications increase by 0.52 from the pre- to the posttreatment period. Using the estimate for the difference between treated and untreated classes, 7.5, in column (1) of 4, we calculate the counterfactual number of applications in treated classes in the absence of compulsory licensing which is equal to $10.19(=7.5+2.17+0.52)$. The treatment effect is 2.5. Thus, the number of patents increased relative to the counterfactual by $24.5 \%(=2.5 / 10.19)$.

${ }^{42}$ The number of patents of young and small increases by $38 \%$ while the number of patents of all other companies increases by $18 \%$.

${ }^{43}$ In unreported regressions we use citation-weighted patents instead of the absolute number of patents and find the same results. Results are available from the authors upon request. 
industry we measure the pure composition effect without the counteracting disincentive effect. The interpretation that the consent decree helped to open up new markets and enabled new start-ups to compete is consistent with historical accounts on the growth of electronics and computers industry in the 1950s and 1960s (Grindley and Teece, 1997).

\section{Case Study: The Diffusion of the Transistor Tech- nology}

In this section we examine the diffusion of the transistor technology because it is a particularly insightful case study for the mechanisms illustrated in the previous sections for three reasons: First, in response to the antitrust lawsuit Bell started already in 1952 to license the transistor technology via standardized non-discriminatory licensing contracts. This creates an interesting variation in the timing of licensing. Second, transistor patents were expected to be particularly important, hence we can estimate how the amount of follow-on innovation varies with patent quality. And finally, under the impression of the antitrust lawsuit Bell was very careful not to engage in exclusionary practices with its transistor patents. Thus, in 1956 the only change for the transistor technology was that the patents were now royalty free. This allows us to examine the isolated impact of a decrease in royalties.

The transistor is arguably the most important invention of Bell Labs. As the most basic element of modern computers, the transistor has been instrumental in the creation of entire industries and its invention heralded the beginning of the information age. The invention of the transistor earned John Bardeen, Walter Brattain, and William Shockley the Nobel Prize in Physics in 1956. They filed patents in June 1948 and announced the invention on July 1 of the same year. The patents were published in 1950 and 1951. Bell, the military, and the research community at large immediately understood the importance and value of the transistor.

Due to the ongoing antitrust lawsuit, Bell's management was reluctant to draw attention to its market power by charging high prices for transistor components or for licenses (Mowery, 2011). To appease the regulator, Bell's top managers agreed to share and license the transistor device with standardized non-discriminatory licensing contracts (Gertner, 2012, p.111). In addition, Bell decided to actively promote the transistor by organizing conferences to explain the technology. In April 1952, over 100 representatives from 40 companies gathered for a nine-day Transistor Technology Symposium, including a visit to Western Electric's transistor manufacturing plant in Allentown, PA. After the conference, 30 companies decided to license the transistor technology for a non-refundable advance payment of $\$ 25,000(\sim \$ 220,000$ in today's 
dollars) that was credited against future royalty payments (Antitrust Subcommittee, 1958, p.2957). Royalty rates amounted to $5 \%$ of the net selling price of the transistor in 1950, which were reduced to 2\% in 1953 (Antitrust Subcommittee, 1959, p. 117).

To be able to separately analyze the transistor we identify among the patents affected by the consent decree all patents related to the original transistor inventor team. There are two main transistor patents: Patent \# 2,524,035 with the title "ThreeElectrode Circuit Element Utilizing Semiconductive Materials" granted in 1950 to John Bardeen and Walter Brattain and Patent \# 2,569,347 with the title "Circuit Element Utilizing Semiconductive Material" issued to William Shockley in 1951. To these two patents, we add all the patents of all researchers who actively worked towards the development of the transistor at Bell Labs. ${ }^{44}$ Then we add all patents from all coauthors. We identify 329 "transistor" patents affected by the consent decree (i.e. held by Bell Labs). This sample is most likely a super-set of all transistor patents. For example, it also includes patent \# 2,402,662 with the title "Light Sensitive Device" granted to Russell Ohl, the original patent of the solar cell. The median publication year of the patents in the transistor subsample is 1947; and 168 of these patents are also included in our baseline sample.

To be able to repeat our regressions in this subsample of transistor patents we extend our baseline sample to patents published up to 1951. For our control group we now use patents with the same number of pre-citations up to 1951 while all other criteria stay the same.

Figure 12 shows the yearly excess citations of transistor patents relative to control group patents. The coefficient of 1952, which is not matched and is close to zero, speaks in favor of parallel trends. The impact of licensing is measurable starting in 1953, and lasts for at least 15 years. This suggests that standardized licensing had a positive impact on follow-on innovation. The fact that the impact does not strongly increase in 1956 when the consent decree reduced licensing fees to zero suggests instead that the price effect of compulsory licensing had little further impact.

Table 5 reports the results from repeating our baseline regression in this subsample. We find that citations to the transistor patents increase by $52 \%$ (column 2). They experience around a four times higher increase in follow-on citations than other consent decree patents. The magnitude of the effect is consistent with the presumption that patents on more important inventions experience a larger increase after compulsory licensing.

Despite the large effects, the transistor patents do not drive the effect in our main sample. To rule out this possibility we analyze our original sample up to 1949 with and without transistor patents. Results are shown in columns (5) and (6). We find large

\footnotetext{
${ }^{44}$ Researchers whom we classify to have actively contributed to the transistor at Bell Labs were in alphabetical order Bardeen, Bown, Brattain, Fletcher, Gardner Pfann, Gibney, Pearson, Morgan, Ohl, Scaff, Shockley, Sparks, Teal and Theurer (e.g. Nelson, 1962).
} 
Figure 12: Annual Treatment Effects on Excess Citations of Transistor Patents

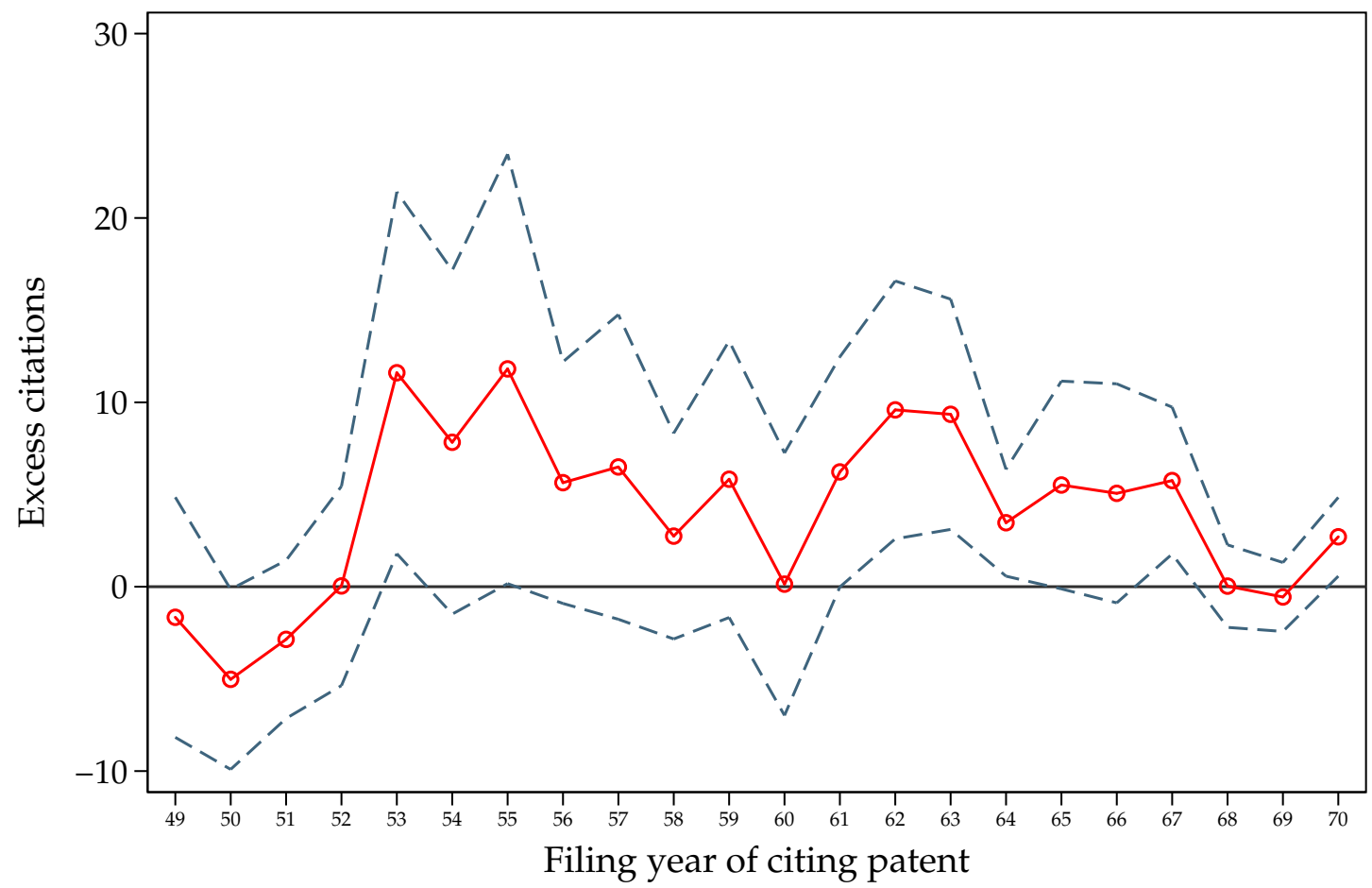

Notes: This graph shows the estimated number of yearly excess citations of transistor-related patents affected by the consent decree ("Bell patents") relative to patents with the same publication year, in the same three-digit USPC primary class and with the same number of citations up to 1951. We define Bell patents as transistor-related if they are either one of the two main transistor patents (Patent \# 2,524,035 or Patent \# 2,569,347) or were filed by inventors associated with these patents or their co-inventors. To arrive at these estimates, we regress the number of citations in each year on an indicator variable that is equal to one if the patent under consideration is affected by the consent decree and year fixed effects. The dashed lines represent the $90 \%$ confidence bands for the estimated coefficient. To adjust for the different number of control patents per treatment patent in each stratum, we use the weights suggested by Iacus et al. (2009). The data are from the Worldwide Patent Statistical Database (PATSTAT) of the European Patent Office. 
Table 5: The Transistor Subsample

\begin{tabular}{|c|c|c|c|c|c|c|}
\hline & (1) & $(2)$ & (3) & $(4)$ & $(5)$ & (6) \\
\hline & \multicolumn{3}{|c|}{ Publication year <1952 } & \multicolumn{3}{|c|}{ Publication year $<1949$} \\
\hline Subsample & $\begin{array}{l}\text { Base- } \\
\text { line }\end{array}$ & Transistor & $\begin{array}{c}\text { No } \\
\text { transistor }\end{array}$ & $\begin{array}{l}\text { Base- } \\
\text { line }\end{array}$ & $\begin{array}{l}\text { Transis- } \\
\text { tor }\end{array}$ & $\begin{array}{c}\text { No } \\
\text { transistor }\end{array}$ \\
\hline Start treatment & 1955 & 1953 & 1955 & 1955 & 1953 & 1955 \\
\hline Bell & $\begin{array}{c}-0.3 \\
(0.3)\end{array}$ & $\begin{array}{l}-1.4 \\
(1.2)\end{array}$ & $\begin{array}{c}-0.4 \\
(0.3)\end{array}$ & $\begin{array}{c}-0.4 \\
(0.5)\end{array}$ & $\begin{array}{l}-0.9 \\
(2.1)\end{array}$ & $\begin{array}{c}-0.4 \\
(0.5)\end{array}$ \\
\hline $\mathrm{I}(53 / 55-60)$ & $\begin{array}{c}-5.7^{* * *} \\
(0.7)\end{array}$ & $\begin{array}{l}-6.3^{* *} \\
(2.7)\end{array}$ & $\begin{array}{c}-5.6^{* * *} \\
(0.7)\end{array}$ & $\begin{array}{c}-6.4^{* * *} \\
(0.6)\end{array}$ & $\begin{array}{l}-7.4^{* * *} \\
(2.2)\end{array}$ & $\begin{array}{c}-6.4^{* * *} \\
(0.6)\end{array}$ \\
\hline $\begin{array}{l}\text { Bell x I(53/55- } \\
60)\end{array}$ & $1.9^{* * *}$ & $8.0^{* *}$ & $1.8^{* * *}$ & $2.0^{* * *}$ & $4.4^{*}$ & $2.0^{* * *}$ \\
\hline Constant & $\begin{array}{c}(0.5) \\
19.0^{* * *} \\
(1.4)\end{array}$ & $\begin{array}{c}(3.7) \\
23.0^{* * *} \\
(3.2) \\
\end{array}$ & $\begin{array}{c}(0.5) \\
18.8^{* * *} \\
(1.4) \\
\end{array}$ & $\begin{array}{c}(0.6) \\
18.3^{* * *} \\
(1.2) \\
\end{array}$ & $\begin{array}{c}(2.3) \\
22.3^{* * *} \\
(2.9) \\
\end{array}$ & $\begin{array}{c}(0.6) \\
18.1^{* * *} \\
(1.2) \\
\end{array}$ \\
\hline \# treated & 5758 & 204 & 5554 & 4533 & 168 & 4365 \\
\hline Clusters & 239 & 65 & 237 & 225 & 58 & 223 \\
\hline Obs. & 1035421 & 64891 & 1021733 & 896556 & 56664 & 886044 \\
\hline
\end{tabular}

Notes: This table shows the results from a difference-in-differences estimation. As the dependent variable we use all citations by companies other than the filing company. For the regression with the transistor patents, we define the treatment period as starting in 1953; for the non-transistor patents we define the treatment period as starting in 1955, as in our main regression in equation (2). Bell is an indicator variable equal to one if a patent is published by a Bell System company before 1949 and is therefore affected by the consent decree. As control patents, we use all patents that were published in the U.S. matched by publication year, primary USPC technology class, and the number of citations. We define patents as transistor patents if they were filed by a member of the original transistor team or one of their co-authors. In the regressions for columns (1) to (3), we use all patents with a publication year before 1952 and we match all citations up to and including 1951. Correspondingly, in the regressions for columns (4) to (6) we use patents and citations up to 1949. The data are from the Worldwide Patent Statistical Database (PATSTAT) of the European Patent Office. All coefficients are multiplied by 100 for better readability. Standard errors are clustered on the primary three-digit USPC technology class level and $*, * *, * * *$ denote statistical significance on $10 \%, 5 \%$ and $1 \%$ level, respectively. 
but insignificant effects for the transistor sample and virtually the same effect without transistors as in the baseline regression that includes transistor patents (column 4). ${ }^{45}$

Transistors are the classical example of a general purpose technology that has the potential of having a large scale impact on the economy (Helpman, 1998). If it had not been for the antitrust lawsuit against Bell, odds are that Bell's licensing policy would have been less accommodating and the follow on-innovations stimulated by the transistors less dramatic than they were.

\section{Conclusion}

In this paper we show that antitrust enforcement can increase innovation. The 1956 consent decree that settled the antitrust lawsuit against Bell increased innovation, mostly by small and young companies building on Bell's established technologies. We conclude that antitrust enforcement can play an important role in increasing innovation by facilitating market entry.

Several antitrust scholars have argued that antitrust enforcement should pay special attention to exclusionary practices because of their negative influence on innovation (Baker, 2012; Wu, 2012). Our study seconds this view. We show that foreclosure has a negative impact on innovation and that compulsory licensing may not be an effective remedy to end market foreclosure and to overcome its stifling effect on innovation unless accompanied by structural remedies.

Compulsory licensing is often imposed in merger cases where the market structure changes endogenously (Delrahim, 2004; Sturiale, 2011). We would expect that if the newly merged company is able to foreclose the product market, compulsory licensing is not an effective remedy. More empirical studies are needed to assess whether the negative effect of market foreclosure on innovation is a first order concern for merger and acquisition cases.

We estimate the negative effects of patents on follow-on innovations by other companies, but we cannot determine how large the incentive effect of patents for the company holding the patent is. In our case, compulsory licensing does not appear to have had a strong negative effect on Bell's patenting activities. It would be surprising if this was the norm (Williams, 2015). But it is consistent with Galasso and

\footnotetext{
${ }^{45}$ The large magnitude of the effect should not be taken at face value. The identifying assumption of this regression is that the control patents would have had the same number of citations as the transistor patents. In our regression this is true for 1953, but given the exceptional nature of the invention of the transistor, it is fair to assume that this trend might have diverged in later years. Furthermore, it is not absolutely clear from the historical records why Bell decided to license the transistor patents. If the licensing decision was taken because of the expectation of important followon research, our estimate might give an upper bound on the effect. For example, Jack Morton, the leader of Bell Labs effort to produce transistors at scale, advocated the sharing of the transistor to benefit from advances made elsewhere. Source: http://www.computerhistory.org/siliconengine/belllabs-licenses-transistor-technology/ (last accessed September 09, 2016).
} 
Schankerman (2015a) who show that large companies do not reduce their innovation activity when their patents are invalidated in court, but do change the direction of their research and development activities.

We analyze a very important antitrust lawsuit from the 1950s. Using a historical setting has the advantage that we can draw on a large number of detailed historical accounts and that we can conduct a long run evaluation many years after the case. At the same time it is unclear whether the size of the effects of compulsory licensing would be similar today. Jaffe and Lerner (2011) suggest that many negative effects of the patent system discussed today are related to regulatory changes surrounding the establishment of the Court of Appeals for the Federal Circuit in 1982. The reforms led to a significant broadening and strengthening of the rights of patent holders and consequently to a surge in the number of patents granted. This makes us think that the effects of compulsory licensing might be even larger today. 


\section{References}

Acemoglu, D. and Akcigit, U. (2012). Intellectual property rights policy, competition and innovation. Journal of the European Economic Association, 10 (1), $1-42$.

Aghion, P., Harris, C., Howitt, P. and Vickers, J. (2001). Competition, imitation and growth with step-by-step innovation. The Review of Economic Studies, 68 (3), 467-492.

Akcigit, U. and KerR, W. R. (2010). Growth through heterogeneous innovations. NBER Working Paper No. 16443.

Alcacer, J. and Gittelman, M. (2006). Patent citations as a measure of knowledge flows: The influence of examiner citations. The Review of Economics and Statistics, 88 (4), 774-779.

- - — and Sampat, B. (2009). Applicant and examiner citations in US patents: An overview and analysis. Research Policy, 38 (2), 415-427.

Antitrust Subcommittee (1958). Consent decree program of the Department of Justice. American Telephone \& Tel. Subcommittee - hearings before the Antitrust Subcommittee. U.S. House Committee on the Judiciary, Committee on the Judiciary Serial No. 9.

Antitrust Subcommittee (1959). Consent decree program of the Department of Justice. Committee on the Judiciary, House of Representatigves, Eighty-Sixth Congress, First Session.

Arora, A., Belenzon, S. and Patacconi, A. (2015). Killing the golden goose? the decline of science in corporate r\&d. NBER Working Paper No. 20902.

BAKer, J. B. (2012). Exclusion as a core competition concern. Antitrust Law Journal, 78, $527-589$.

Delrahim, M. (2004). Forcing firms to share the sandbox: Compulsory licensing of intellectual property rights and antitrust. European Business Law Review, 15 (5), 1059-1069.

Foster, L., Haltiwanger, J. and Krizan, C. J. (2006). Market selection, reallocation, and restructuring in the us retail trade sector in the 1990s. The Review of Economics and Statistics, 88 (4), 748-758.

Galasso, A. (2012). Broad cross-license negotiations. Journal of Economics 65 Management Strategy, 21 (4), 873-911. 
- and Schankerman, M. (2015a). Patent rights and innovation by small and large firms. NBER Working Paper No. 21769, (21769).

- and - (2015b). Patents and cumulative innovation: Causal evidence from the courts. The Quarterly Journal of Economics, 130 (1), 317-369.

Gans, J. S., Hsu, D. H. and Stern, S. (2002). When does start-up innovation spur the gale of creative destruction? The RAND Journal of Economics, 33 (4), 571-586.

- , - and - (2008). The impact of uncertain intellectual property rights on the market for ideas: Evidence from patent grant delays. Management Science, 54 (5), 982-997.

— and Stern, S. (2003). The product market and the market for ideas: commercialization strategies for technology entrepreneurs. Research policy, 32 (2), 333-350.

Gertner, J. (2012). The idea factory: Bell Labs and the great age of American innovation. Penguin.

Grindley, P. C. and Teece, D. J. (1997). Licensing and cross-licensing in semiconductors and electronics. California Management Review, 39 (2), 8-41.

Hall, B. H., Jaffe, A. B. and Trajtenberg, M. (2001). The nber patent citation data file: Lessons, insights and methodological tools. NBER Working Paper No. 8498 .

Helpman, E. (1998). General purpose technologies and economic growth. MIT press.

Holbrook, D., Cohen, W. M., Hounshell, D. A. and Klepper, S. (2000). The nature, sources, and consequences of firm differences in the early history of the semiconductor industry. Strategic Management Journal, 21 (10-11), 1017-1041.

Iacus, S. M., King, G. and Porro, G. (2009). Cem: Software for coarsened exact matching. Journal of Statistical Software, 30 (9), 1-27.

- - - and - (2012). Causal inference without balance checking: Coarsened exact matching. Political Analysis, 20, 1-24.

Imbens, G. W. and Rubin, D. B. (2015). Causal inference in statistics, social, and biomedical science. Cambridge University Press.

JAFFe, A. B. and LeRner, J. (2011). Innovation and its discontents: How our broken patent system is endangering innovation and progress, and what to do about it. Princeton University Press. 
KERR, W. R. (2008). Ethnic scientific communities and international technology diffusion. The Review of Economics and Statistics, 90 (3), 518-537.

Kogan, L., Papanikolaou, D., Seru, A. and Stoffman, N. (2012). Technological innovation, resource allocation, and growth. NBER Working Paper No. 17769.

Lanjouw, J. O. and Schankerman, M. (2004). Protecting intellectual property rights: Are small firms handicapped? Journal of Law and Economics, 47 (1), 4574 .

Lerner, J. (1994). The importance of patent scope: An empirical analysis. The RAND Journal of Economics, 25, 319-333.

Moser, P. and Voena, A. (2012). Compulsory licensing: Evidence from the trading with the enemy act. American Economic Review, 102 (1), 396-427.

- - - and Waldinger, F. (2014). German jewish emigres and US invention. American Economic Review, 104 (10), 3222-3255.

Mowery, D. C. (2011). Federal policy and the development of semiconductors, computer hardware, and computer software: A policy model for climate change r\&d? In Accelerating Energy Innovation: Insights from Multiple Sectors, University of Chicago Press, pp. 159-188.

Murray, F. and Stern, S. (2007). Do formal intellectual property rights hinder the free flow of scientific knowledge?: An empirical test of the anti-commons hypothesis. Journal of Economic Behavior \& Organization, 63 (4), 648-687.

NeLson, R. (1962). The link between science and invention: The case of the transistor. In The rate and direction of inventive activity: Economic and social factors, Princeton University Press, pp. 549-584.

Nelson, R. R. (1959). The simple economics of basic scientific research. Journal of Political Economy, 67 (3), 297-306.

Noll, A. (1987). Bell system r\&d activities. Telecommunications Policy, 11 (2), 161 $-178$.

Rosenberg, N. (1990). Why do firms do basic research (with their own money)? Research Policy, 19 (2), 165-174.

Sampat, B. and Williams, H. L. (2015). How do patents affect follow-on innovation? evidence from the human genome. NBER Working Paper No. 21666.

Segal, I. and Whinston, M. D. (2007). Antitrust in innovative industries. American Economic Review, 97 (5), 1703-1730. 
Sturiale, J. E. (2011). Compulsory licensing of intellectual property as merger remedy: A decision-theoretic approach. Louisiana Law Review, 72, 605-646.

Temin, P. and Galambos, L. (1987). The fall of the Bell system: A study in prices and politics. Cambridge University Press.

Waller, S. W. and SAg, M. (2014). Promoting innovation. Iowa Law Review, 100, $2223-2247$.

Wessner, C. W. et al. (2001). Capitalizing on new needs and new opportunities: Government-industry partnerships in biotechnology and information technologies. National Academies Press, chapter 2 available at http://www.nap.edu/read/10281/chapter/11.

Williams, H. L. (2015). Intellectual property rights and innovation: Evidence from health care markets. In Innovation Policy and the Economy, Volume 16, University of Chicago Press.

Wu, T. (2012). Taking innovation seriously: Antitrust enforcement if innovation mattered most. Antitrust Law Journal, 78 (2), 313-328. 


\section{APPENDICES}

\section{A Appendix to Section 2}

\section{A.1 Compulsorily Licensed Patents by NBER Technological Subcategory}

Figure 13: Compulsorily Licensed Patents by NBER Technological Subcategory


Notes: The pie chart shows the distribution of compulsorily licensed patents over 35 NBER technological subcategories. The legend is sorted from largest share to smallest. The categorization in technological subcategories is based on US patent classifications, following Hall et al. (2001). The data are from the Worldwide Patent Statistical Database (PATSTAT) of the European Patent Office. 


\section{A.2 Patenting of Bell in Radar and Cryptography}

Figure 14: War Technologies Created by Bell Labs

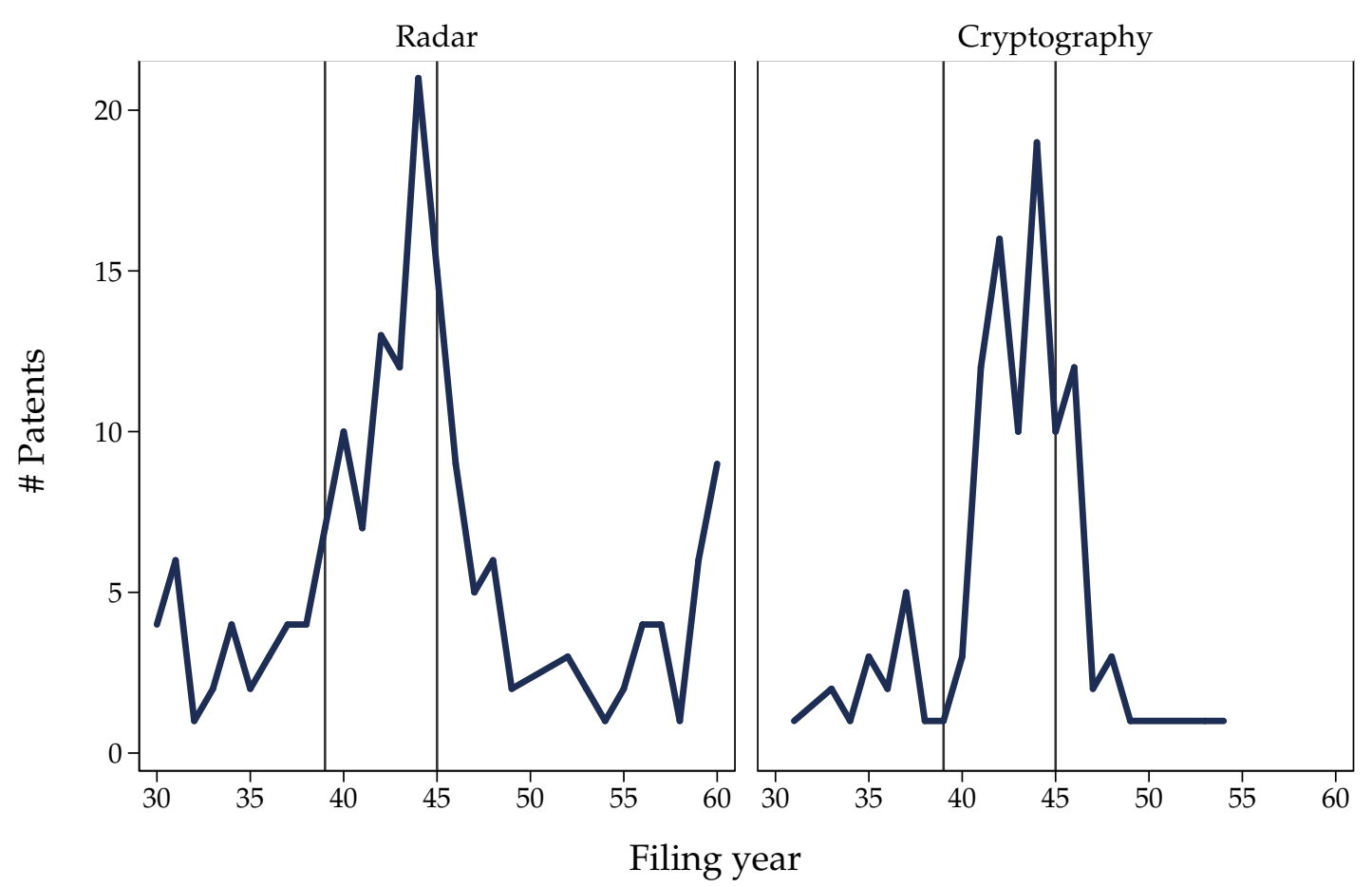

Notes: This figure shows the yearly number of Bell patents relating to radar and cryptography, two technologies relevant for World War II. We identify both technologies by their USPC class: We use the class 342 titled "Communications: directive radio wave systems and devices (e.g., radar, radio navigation)" to classify radar and class 380 titled "Cryptography" to classify cryptography. The data are from the Worldwide Patent Statistical Database (PATSTAT) of the European Patent Office.

\section{B Appendix to Section 4}

\section{B.1 Comparing the Average Number of Citations of Treat- ment and Control Patents}

In Figure 15 we compare the evolution of patent citations to Bell patents and control patents in the same publication year and the same four digit technology class. We use the weights proposed of Iacus et al. (2009) to adjust for the different number of control patents for each Bell patent. From 1949 to 1953, the average number of citations of treatment and control patents track each other very closely. This implies that the Bell patents and the control patents exhibit a parallel trend in citations in the first 4 years after the plea. The two lines diverge in 1954, with Bell patents receiving relatively more citations than control patents, and they converge again in 1961/1962. This is prima facie evidence for an effect from 1954 onward. 
Figure 15: Average Number of Citations to Bell and Control Patents Published before 1949

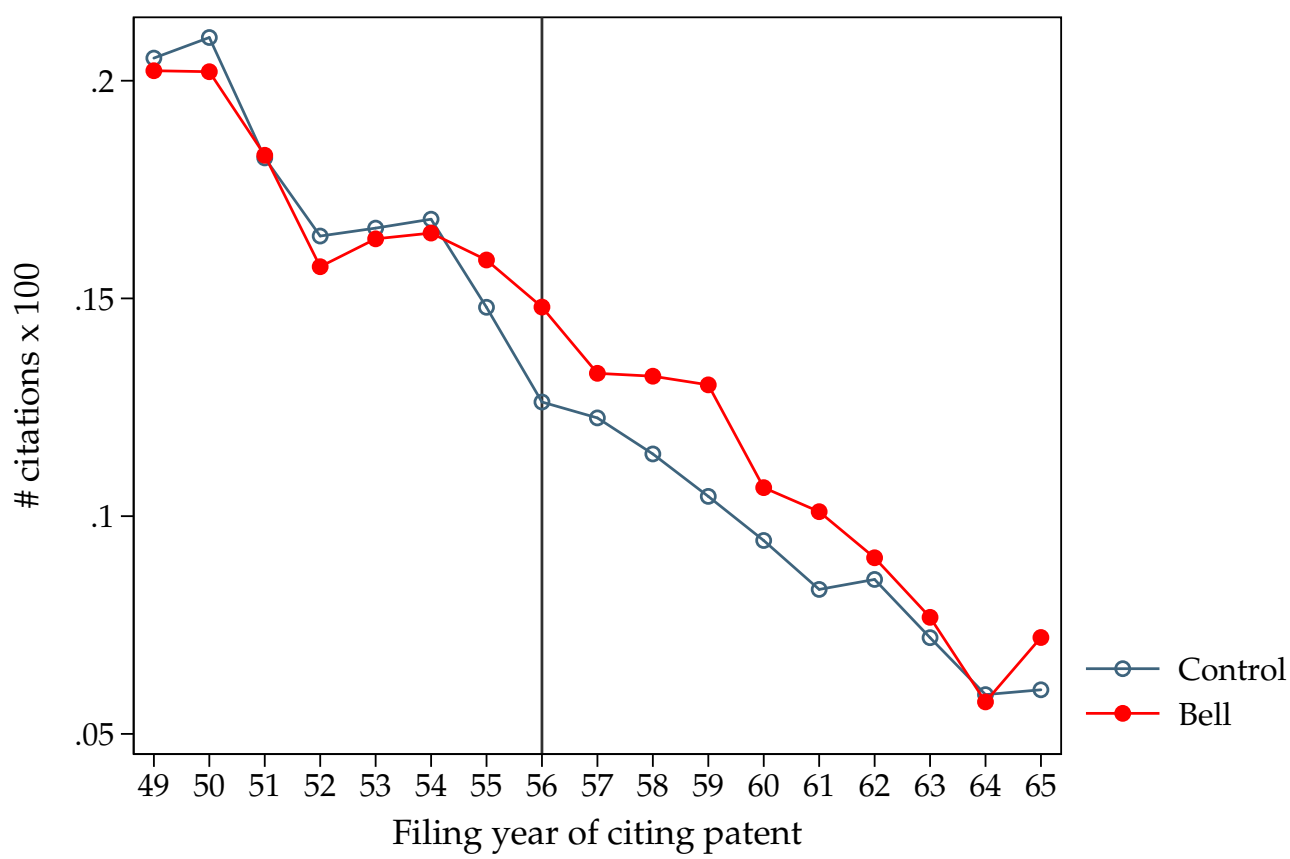

Notes: This figure shows average patent citations of patents published before 1949 in every year after publication. The line with solid circles shows patent citations of the treated patents (Bell patents) and the line with empty circles shows patent citations of control patents, with the same publication year and the same four digit technology class as the Bell patents. For aggregation we use the weights of Iacus et al. (2009) to adjust for a different number of control patents for each Bell patent. The data are from the Worldwide Patent Statistical Database (PATSTAT) of the European Patent Office. 


\section{B.2 Pseudo Outcomes: Unaffected Companies have no Ex- cess Citations}

In the main part of the text we use time varying coefficients to show that there are no yearly excess citations from the B-2 companies, which were exempt from the compulsory licensing agreement. In column (2) of Table 6 we estimate the average effect for these companies and find none. There are also two other groups of companies that were to a lesser degree affected by the consent decree: foreign companies and companies that already had licensing agreements in place. ${ }^{46}$ Foreign companies could license for free but did not receive any technical description or assistance from Bell. ${ }^{47}$ In Table 6 we show the results using as the dependent variable the citations from from foreign companies in column (3) and from companies that had a license before the consent decree in column (4). In the last column we use data on all companies that did not have a license from Bell. We do not find a measurable effect for foreign companies or companies with a license and a large effect for companies without a license.

\footnotetext{
${ }^{46}$ All companies with a license agreement are listed in the hearing documents (Antitrust Subcommittee, 1958, p. 2758).

${ }^{47}$ Verbatim in the consent decree "The defendants are each ordered and directed (...) to furnish to any person domiciled in the United States and not controlled by foreign interests (...) technical information relating to equipment (...)".
} 
Table 6: The Effect of Compulsory Licensing on Subsequent Citations of Unaffected Companies

\begin{tabular}{lccccc}
\hline & $(1)$ & $(2)$ & $(3)$ & $(4)$ & $(5)$ \\
& Base- & B-2 & Foreign & Li- & No \\
& line & Companies & companies & cense & license \\
\hline Treatment & -0.4 & -0.1 & -0.0 & $0.5^{* * *}$ & $-0.9^{* *}$ \\
& $(0.5)$ & $(0.2)$ & $(0.1)$ & $(0.2)$ & $(0.4)$ \\
I(55-60) & $-6.4^{* * *}$ & $-1.2^{* * *}$ & $2.1^{* * *}$ & $-1.1^{* * *}$ & $-5.4^{* * *}$ \\
& $(0.6)$ & $(0.2)$ & $(0.3)$ & $(0.2)$ & $(0.5)$ \\
T x I(55-60) & $2.0^{* * *}$ & 0.2 & -0.0 & 0.4 & $1.6^{* * *}$ \\
& $(0.6)$ & $(0.1)$ & $(0.2)$ & $(0.3)$ & $(0.5)$ \\
Constant & $18.3^{* * *}$ & $2.3^{* * *}$ & $0.9^{* * *}$ & $3.1^{* * *}$ & $15.2^{* * *}$ \\
& $(1.2)$ & $(0.3)$ & $(0.1)$ & $(0.3)$ & $(1.0)$ \\
\hline \# treated & 4533 & 4598 & 4533 & 4533 & 4533 \\
Clusters & 225 & 225 & 225 & 225 & 225 \\
Obs. & 896556 & 1096212 & 896556 & 896556 & 896556 \\
\hline
\end{tabular}

Notes: This table shows the results from a difference-in-differences estimation with years 1949-1954 as pre-treatment period and 1955-1960 as treatment period. The estimation equation is

$$
\text { \#Citations }_{i, t}=\beta_{1} \cdot \text { Bell }_{i}+\beta_{2} \cdot I[1955-1960]+\beta_{3} \cdot \text { Bell }_{i} \cdot I[1955-1960]+\varepsilon_{i, t}
$$

where $I[1955-1960]$ is an indicator variable for the treatment period 1955-1960. The variable "Bell" is an indicator variable equal to one if a patent is published by a Bell System company before 1949 and therefore treated by the consent decree. As dependent variable we use in the first column all citations by companies other than the filing company. In the second column we use all citations of companies exempt from the consent decree (GE, RCA, Westinghouse \& ITT) and in the third column all citations of foreign companies. In the fourth column we use citations of companies that had no licensing agreement with any Bell company prior to the consent decree and in the last column we look at the citation of companies that had a licensing agreement. As control patents, we use all patents that were published in the U.S. matched by publication year, primary United States Patent Classification (USPC) technology class and the number of citations up to 1949. The data are from the Worldwide Patent Statistical Database (PATSTAT) of the European Patent Office. All coefficients are multiplied by 100 for better readability. Standard errors are clustered on the three-digit USPC technology class level and $*, * *, * * *$ denote statistical significance on $10 \%, 5 \%$ and $1 \%$ level, respectively.

\section{B.3 Pseudo Treatment: Citation Substitution is Small.}

One possible interpretation of our estimates is that due to the free availability of Bell technology, companies substituted away from other, potentially more expensive technologies. If this were the case, we should find a negative impact of the consent decree on citations of similar patents of other companies. ${ }^{48}$ To see if this is the case, we assign a pseudo treatment to the patents of GE, RCA, Westinghouse, which were part of the B-2 agreement, and ITT. These companies were among the largest patenting firms in the ten technology classes in which Bell had most patents between 1939 and 1949. Results are reported in Table 7, column (2). We find no effect, implying that

\footnotetext{
${ }^{48}$ This approach is suggested by Imbens and Rubin (2015).
} 


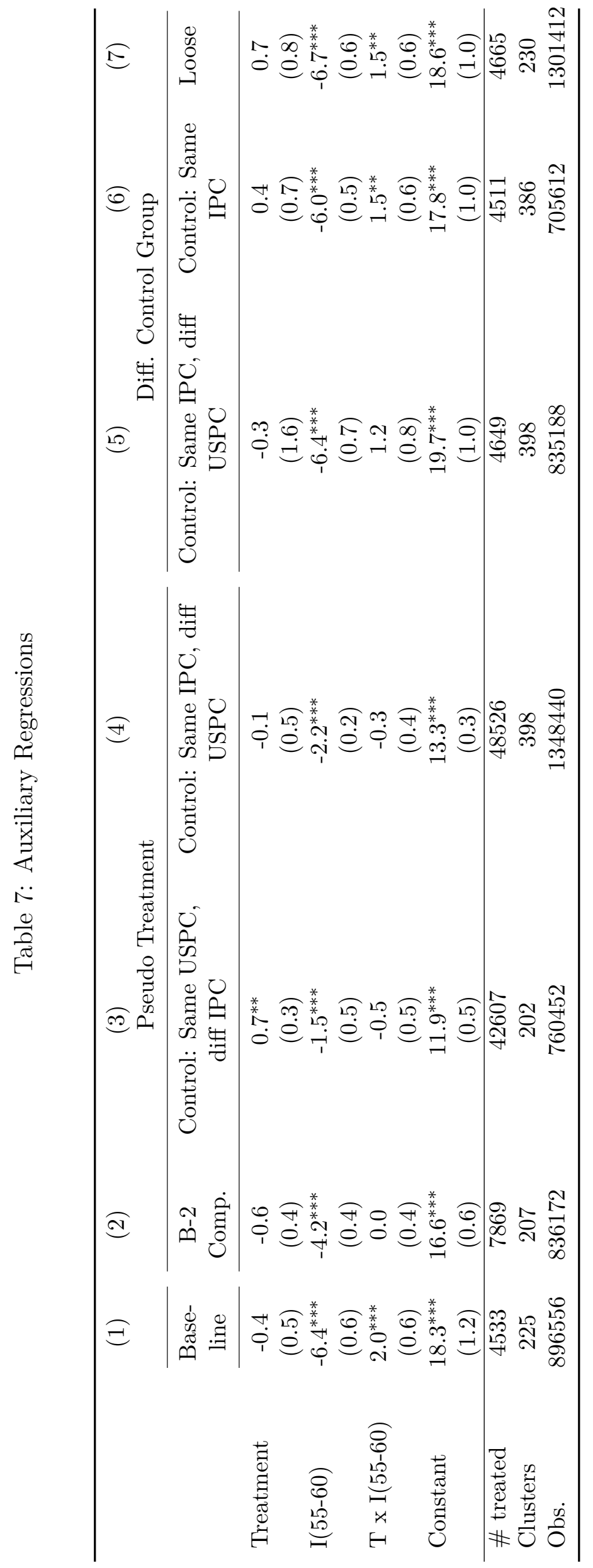

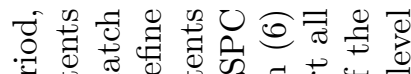

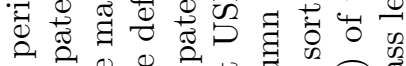

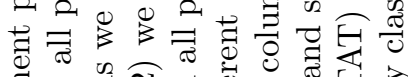

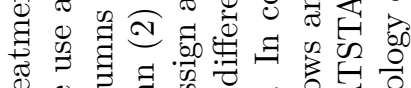

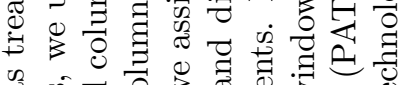

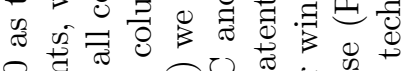
造焉

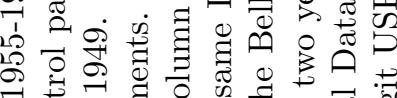

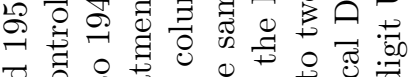

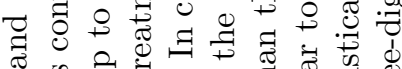

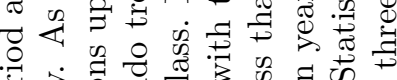

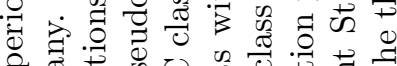

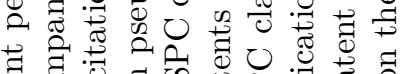

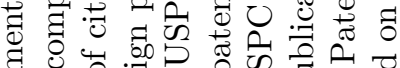

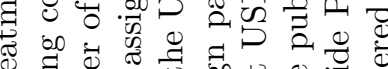

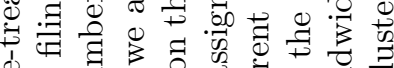

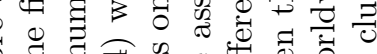

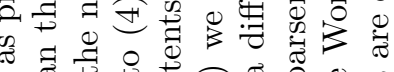

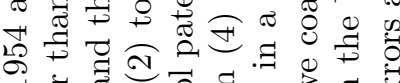
宊

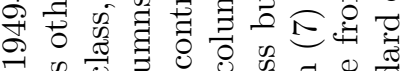
罂.

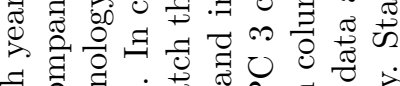
节 总 so

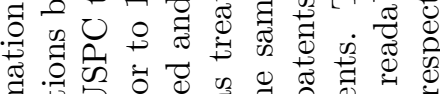

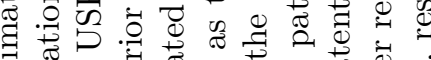

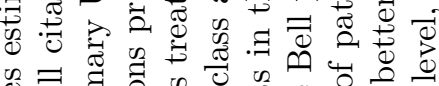

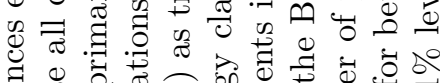

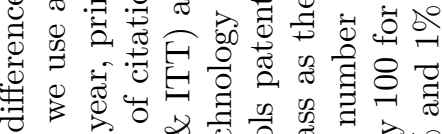

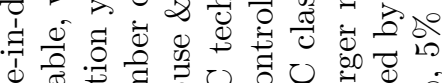

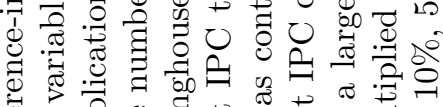

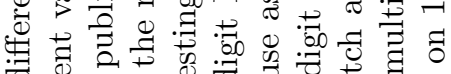

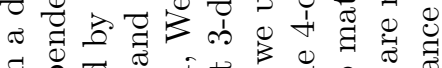

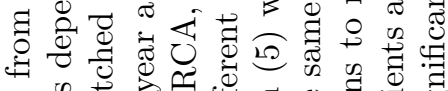

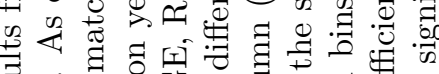

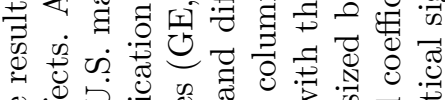

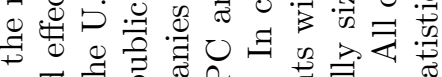

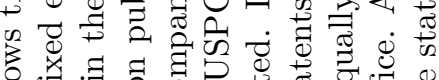

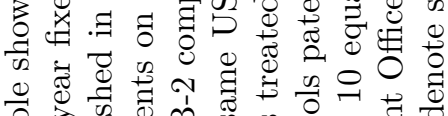

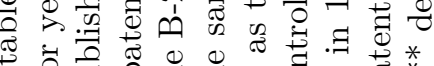

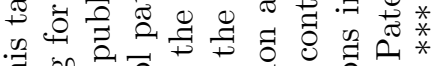
然资 \%

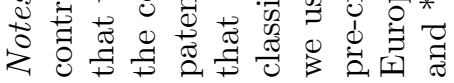


the citation substitution is either small or homogeneous to patents of these companies and the control group.

For a second approach, we exploit the fact that a patent's technology is classified twice: once in the USPC system, which has a technical focus, and once in the IPC system, which reflects more closely the intended industry or profession ("usage") (Lerner, 1994). In columns (3) and (4) of Table 7 we assign a pseudo-treatment to all patents that have the same USPC class and the same IPC class as the Bell patents. As control group we use in column (3) patents with the same USPC, but a different IPC classification as Bell patents. In column (4) we use as a control group patents with the same IPC, but a different USPC classification as Bell patents. Thus we compare patents that are arguably more similar to the Bell patents to two different control groups. We find a small, negative but statistically insignificant effect. Again, this speaks in favor of limited citation substitution or - alternatively - a homogeneous citation substitution to all control groups.

\section{B.4 Effects are Robust to Different Matching Strategies.}

In columns (5) to (7) of Table 7 and in Figure 16 we report results from using several alternative matching variables. In the main specification, we use the age (measured by the publication year), the technology (measured by USPC class) and the quality of a patent (measured by the number of citations up to 1949). In column (6) we use patents in the same IPC but different USPC class instead of using those in the same USPC class. In column (7) we match on the IPC classification, independent of the USPC class. Finally, in column (8) we do a coarsened exact matching in order to match all Bell patents. ${ }^{49}$ In all three cases the size of the effects is similar to the one in the main specification. In Figure 16 we show the size of the treatment effects for different combinations of background variables as proxy for age, technology and quality. On the vertical axis we plot the number of matched patents. The coefficient is mostly around 2 .

\footnotetext{
${ }^{49}$ Coarsened exact matching was proposed by Iacus et al. (2012). In this specification we match on one of five publication year categories that contain 2 years each and one of 10 prior-citation categories.
} 
Figure 16: Treatment Effects for Different Matching Variables

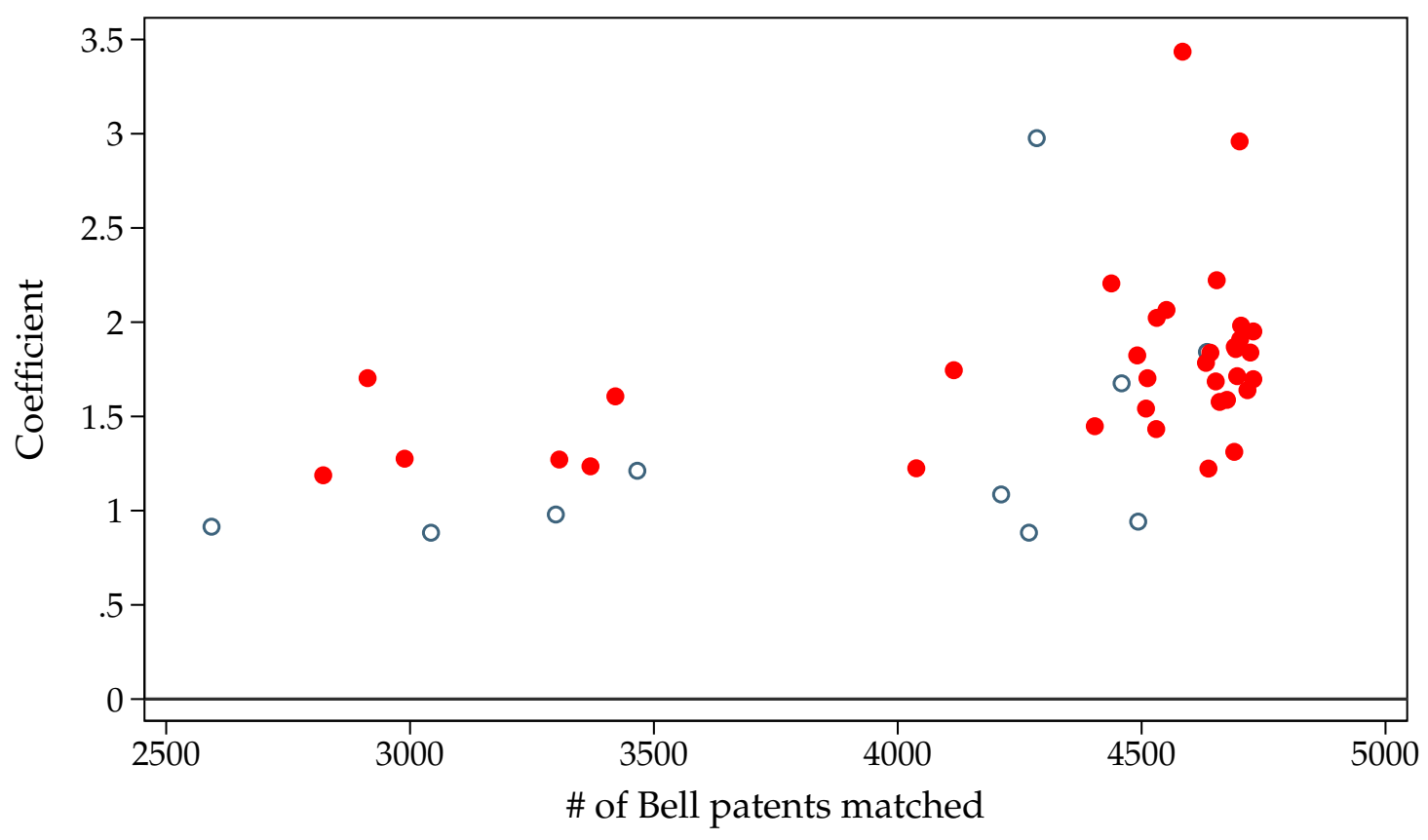

- Significant on $10 \%$ level $\circ$ Insignificant

Notes: In this figure we plot the parameter estimates from difference-in-differences estimations of the impact of the consent decree for different matching strategies, controlling for year fixed effects. As before, as dependent variable we use all citations by companies other than the filing company. In all regressions, we use a measure for the age, the technology and the quality of a patent for matching. As measures for the age of a patent, we alternatively use application year, publication year or both. For technology, we use the USPC, the USPC with subclasses, the three and the four digit IPC. As a measure of quality, we use the number of pre-citations as exact numbers, coarsened to steps of five citations and an indicator for at least one citation prior to 1949. The horizontal axis displays the number of matched Bell patents. Empty symbols are insignificant and full symbols are significant at the $10 \%$ level. The data are from the Worldwide Patent Statistical Database (PATSTAT) of the European Patent Office. 


\section{B.5 Patenting Behavior of Bell Relative to Comparable Com- panies}

Figure 17: Patenting of Bell System and B-2 Companies without RCA

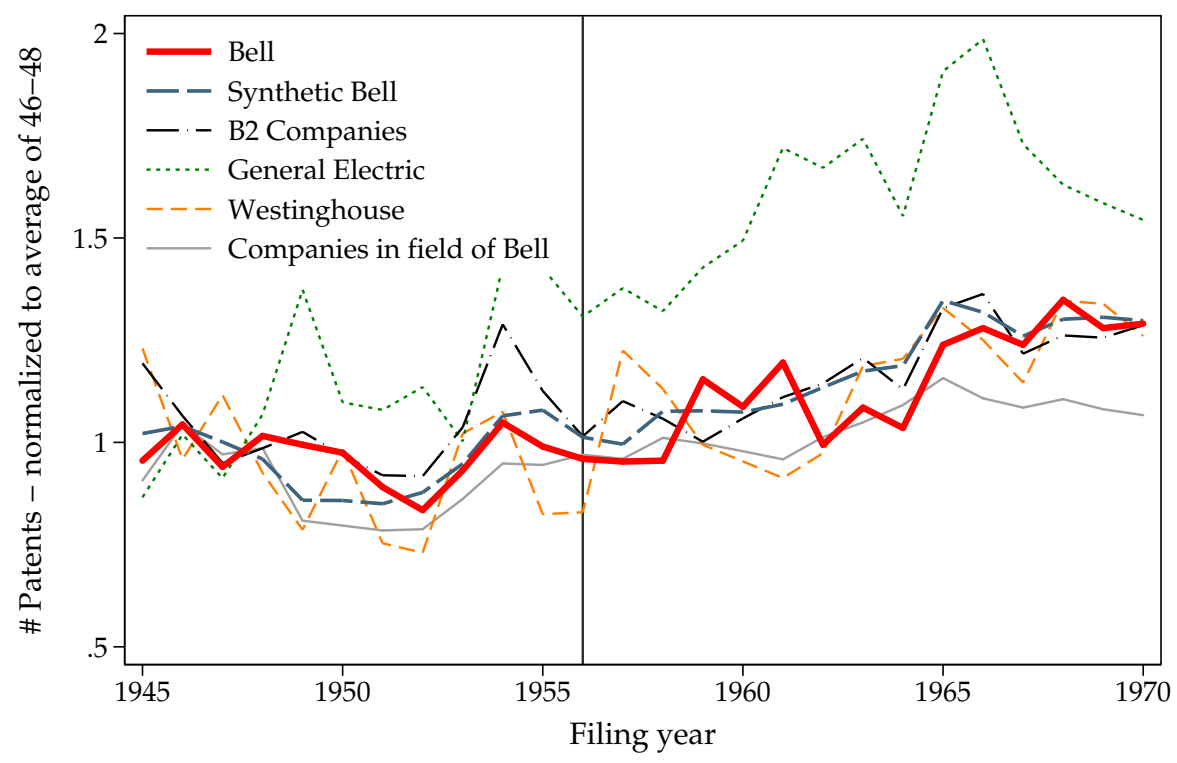

Notes: In this figure we compare Bell's total patenting to a synthetic Bell, the number of patents filed by the B-2 companies (General Electric, Westinghouse, RCA and ITT), General Electric and Westinghouse separately and all companies that existed before 1949 and had at least 100 patents in any field in which Bell was active. The number of patents are normalized to the average number of patents from 1946-1948. We show General Electric and Westinghouse separately, because RCA had a consent decree involving patents in 1958 and thus might have changed its behavior. The data are from the Worldwide Patent Statistical Database (PATSTAT) of the European Patent Office. 


\section{B.6 Share of Communication Patents Measured with NBER Technology Subcategories}

Figure 18: Share of Communication Patents

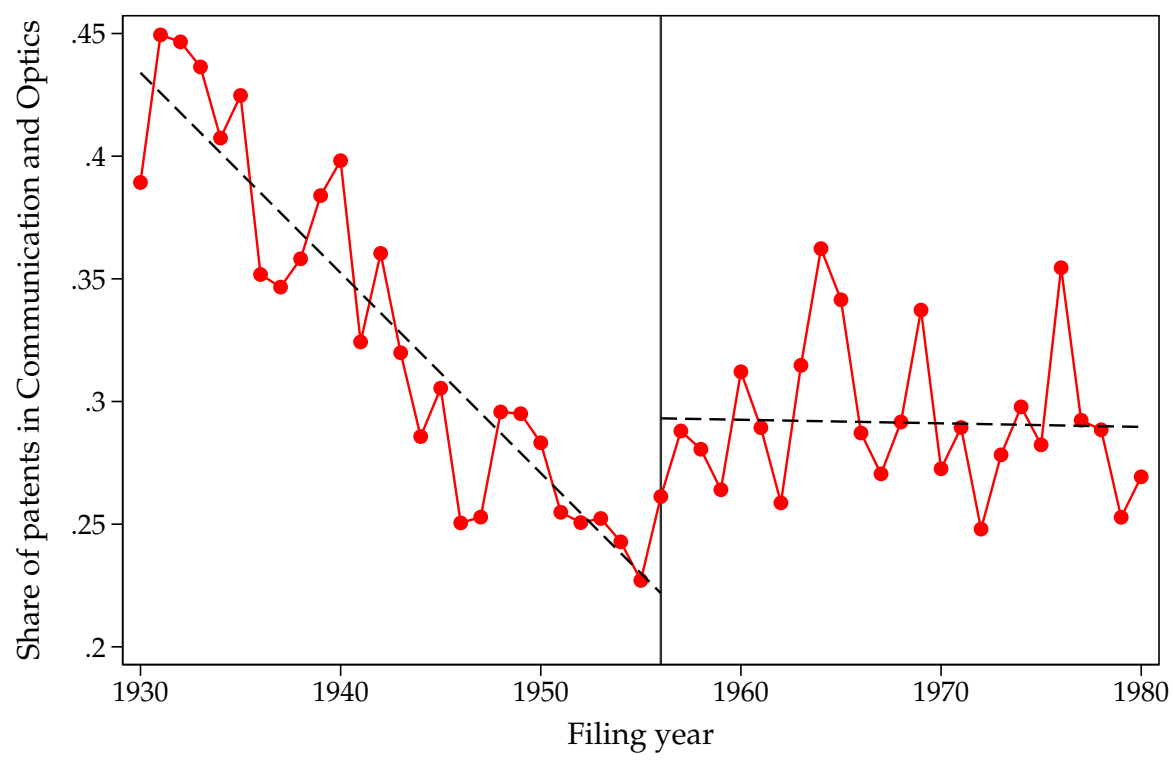

Notes: This figure shows the share of patents related to communication relative to all patents filed by Bell. We define technologies related to communication as the NBER subcategories "Communication" and "Optics" (Hall et al., 2001). We include "Optics" because after the invention of the laser at Bell Labs in 1958, Bell officials predicted correctly that optics might be crucial for the future of communication (Gertner, 2012, p. 253).

\section{B.7 Effect for different definitions of small and young as- signees}

In Figure 19 we estimate the main treatment coefficient separately for citations of different size and age groups of assignees. We find that the effect is driven mainly by companies and individual inventors without patents before 1949 and companies and individual inventors that are less than one year old at the time of the citations.

\section{Appendix to Section 5}

\section{C.1 Effect by NBER Technology Subcategory}

In this section we estimate our main treatment effect separately for citations of patents in different NBER technology subcategories. The results are reported in Figure 20. The increase in citations comes mainly from technologies related to electrical components, in particular in "Electrical Devices". Yet, there is no increase in citations by patents in the subcategory of "Communication". These results corroborate the find- 
Figure 19: Sample split by characteristics of citing firm

(a) By size of patent portfolio in 1949

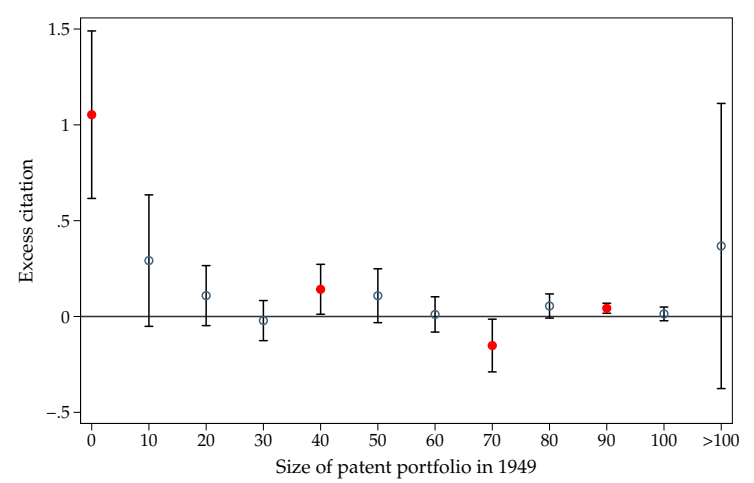

(b) By age of company at citation

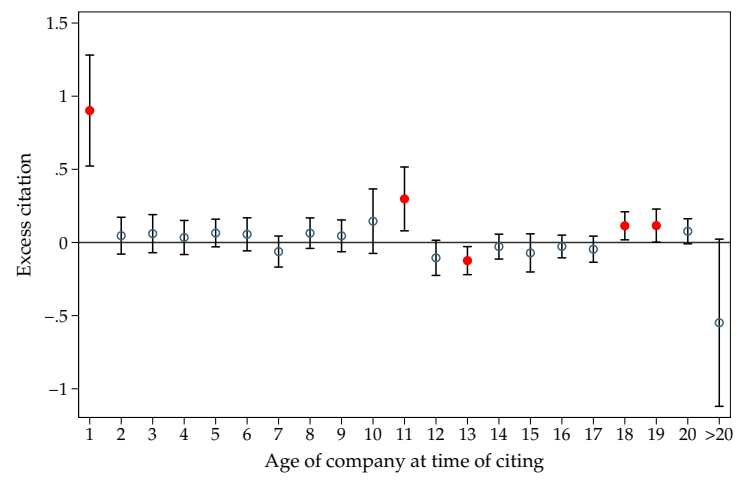

Notes: These Sub-figures show results from a difference-in-differences estimation with the years 19491954 as pre-treatment period and 1955-1960 as treatment period, controlling for year fixed effects. As dependent variable we use all citations by companies other than the filing companies with a specific size of their patent portfolio (Sub-Figure (a)) and a specific company age (b) as indicated in the figure. As control patents we use all patents that were published in the U.S. matched by publication year, primary USPC technology class, and the number of citations up to 1949. The data are from the Worldwide Patent Statistical Database (PATSTAT) of the European Patent Office.

ing in our main text that there is no increase in follow-on innovation in industries concerned with production of communication equipment, the core business of Bell.

\section{C.2 No Lack of Follow-on Innovation in Telecommunications}

This section presents evidence that the null effect in telecommunications was not due to a lack in potential follow-on innovation in the telecommunications market. To do this we look at the total number of citations, the sum of citations of other companies and self-citations, to Bell patents inside and outside of telecommunications. In Subfigure (a) of Figure 21 we plot the average number of total citations to Bell patents related to communication and related to other fields. We use the concordance of Kerr (2008) to assign to each Bell patent the most likely SIC code. We find that the total number of citations to telecommunications patents of Bell were at least as high as to patents outside of communication. This speaks against a low quality of compulsorily licensed patents as a reason for the lack in follow-on innovation in telecommunications. In Subfigure (b) we show that the total number of patent citations to Bell's patents inside and outside of telecommunications were also almost identical before and after the consent decree. This suggests that after the consent decree the potential for followon innovation was not significantly lower in telecommunications than in other fields. 
Figure 20: Effect of Compulsory Licensing on Subsequent Citations By NBER Technological Subcategory

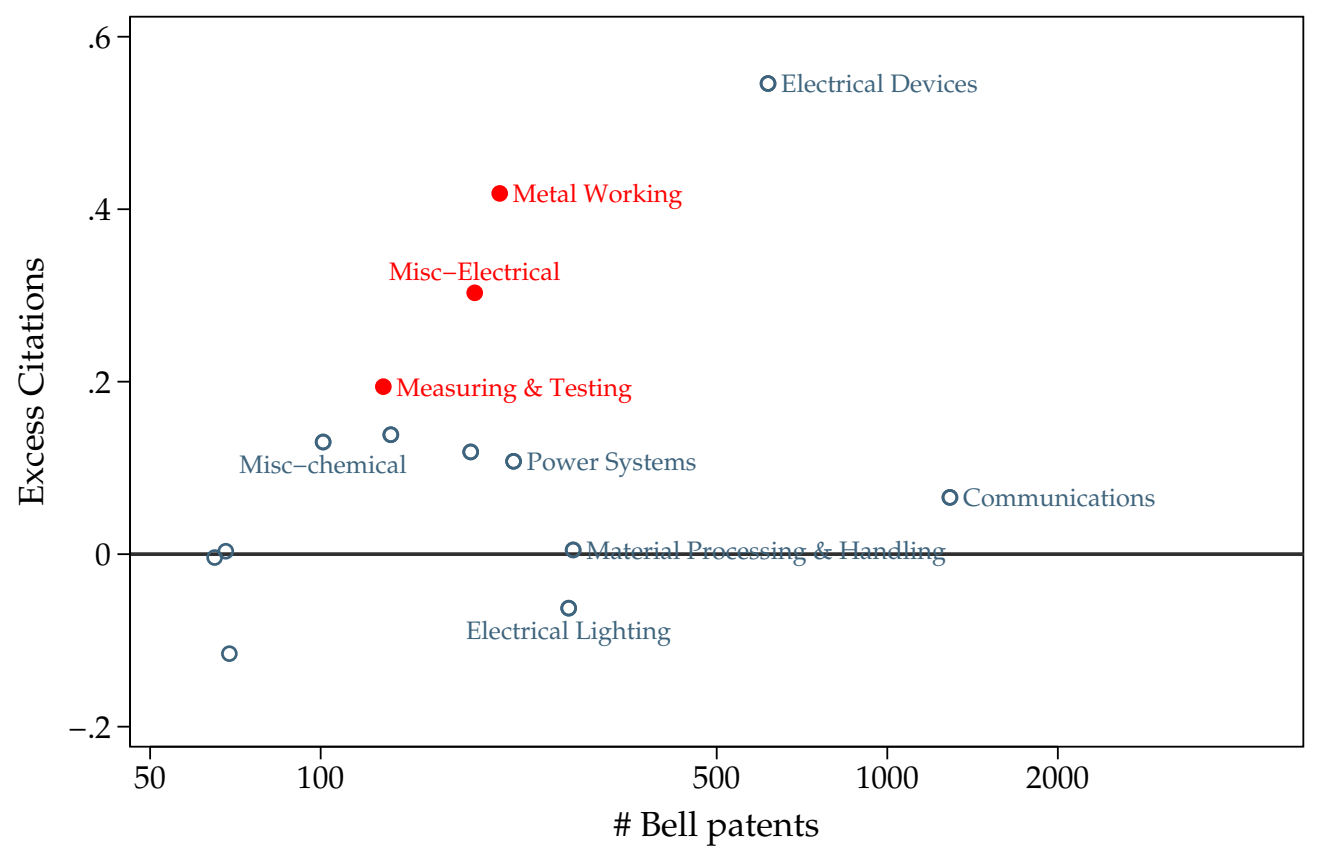

Notes: This figure shows difference-in-differences estimates of the impact of the consent decree on citations from patents in different NBER technological subcategories, controlling for year fixed effects. As dependent variable we use all citations by companies other than the filing company. As control patents we use all patents that were published in the U.S., matched by publication year, primary USPC technology class, and the number of citations up to 1949. A solid circle means that the coefficient is significant at the $10 \%$ level. We split the citing patents by NBER technology subcategory following Hall et al. (2001). The data are from the Worldwide Patent Statistical Database (PATSTAT) of the European Patent Office. 
Figure 21: Number of Citations to Bell Patents Inside and Outside of Communication

(a) Up to 1949

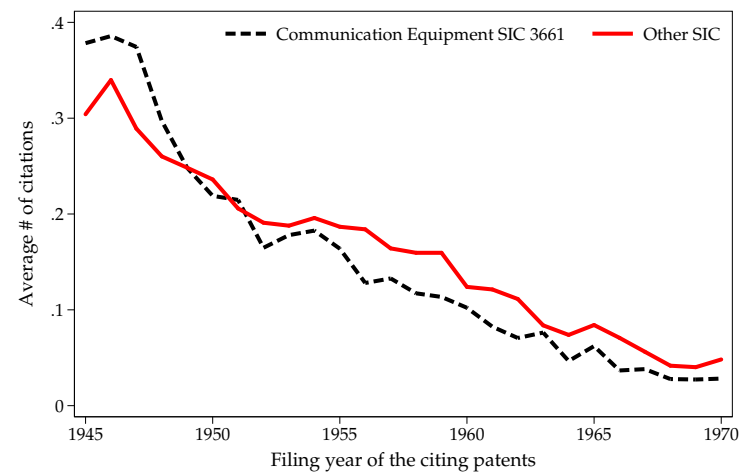

(b) All Bell Patents

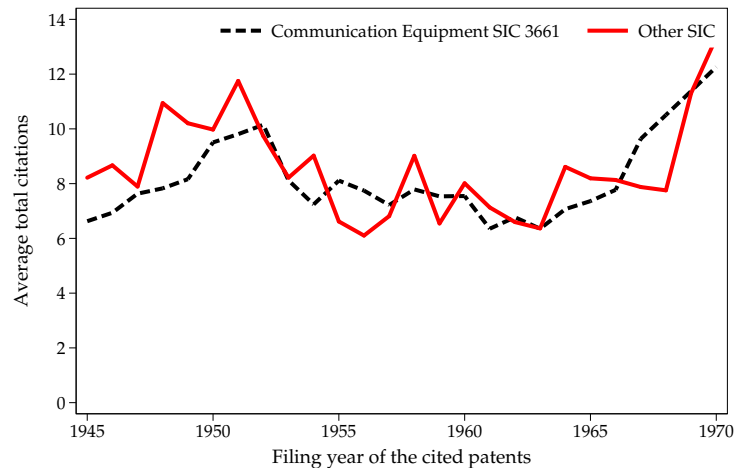

Notes: Sub-figure (a) shows the average number of citations per year for all Bell patents that are most likely used in the production of communication equipment (SIC 3661) and that are used in any other industry. To classify a patent by its most likely industry, we use the data of Kerr (2008) to assign to each USPC class the most likely four-digit SIC industry in which it is used. Sub-figure (b) shows the total number of citations to Bell patents inside and outside of telecommunication filed in a particular year. In this graph we use total citations, the sum of citations from other companies and from Bell to its own patents. The data stem from the Worldwide Patent Statistical Database (PATSTAT) of the European Patent Office. 